\title{
Renewable Energy-Enabled Cellular Networks
}

This paper was downloaded from TechRxiv (https://www.techrxiv.org).

\section{LICENSE}

CC BY 4.0

SUBMISSION DATE / POSTED DATE

31-08-2021 / 01-09-2021

\section{CITATION}

Ko, Young-Chai; Jung, Kug-Jin; Park, Ki Hong; Alouini, Mohamed-Slim (2021): Renewable Energy-Enabled Cellular Networks. TechRxiv. Preprint. https://doi.org/10.36227/techrxiv.16550607.v1

DOI 


\title{
Renewable Energy-Enabled Cellular Networks
}

\author{
Kug-Jin Jung, Student Member, IEEE, Ki-Hong Park, Senior Member, IEEE, \\ Young-Chai Ko, Senior Member, IEEE and Mohamed-Slim Alouini, Fellow Member, IEEE,
}

\begin{abstract}
Renewable energy (RE)-powered base stations (BSs) have been considered as an attractive solution to address the exponential increasing energy demand in cellular networks while decreasing carbon dioxide $\left(\mathrm{CO}_{2}\right)$ emissions. For the regions where reliable power grids are insufficient and infeasible to deploy, such as aerial platforms and harsh environments, RE has been an alternative power source for BSs. In this survey paper, we provide an overview of RE-enabled cellular networks, detailing their analysis, classification, and related works. First, we introduce the key components of RE-powered BSs along with their frequently adopted models. Second, we analyze the proposed strategies and design issues for RE-powered BSs that can be incorporated into cellular networks and categorize them into several groups to provide a good grasp. Third, we introduce feasibility studies on RE-powered BSs based on the recent literature. Fourth, we investigate RE-powered network components other than terrestrial BSs to address potential issues regarding RE-enabled networks. Finally, we suggest future research directions and conclusions.
\end{abstract}

Index Terms-Cellular networks, Renewable energy, Base station, Networks design

\section{INTRODUCTION}

As the number of mobile subscribers has increased from 3.6 billion in 2014 to 5.2 billion in 2020, the increasing number of mobile devices, which are used for data-hungry applications, e.g., social network, video streaming, multimedia content and cloud storage, has brought exponential growth in data traffic [1]. Especially, the increased traffic has contributed to not only the continuous expansion of network capacity demand but also the surge in the energy consumption of the information and communication technology (ICT) sector. As mobile data traffic is estimated to increase at a compound annual growth rate of $46 \%$ from 2017 to 2022 [2], the exponential surge in energy consumption is expected to reach $20 \%$ of the total electricity consumption by 2030 [3]. As shown in Fig. 1, the base station (BS) consumes nearly $60 \%$ of energy in a wireless cellular network. Therefore, reducing the energy consumption of BSs can increase revenue for mobile network operators (MNOs).

Over the last six years, the number of BSs in the world increased from 4 million to 5 million, and every year they generate over a hundred million tons of carbon dioxide equivalent $\left(\mathrm{CO}_{2} \mathrm{e}\right)$ [5], exacerbating global warming and climate change. Under the Paris Agreement, countries agreed to limit global warming to below $1.5^{\circ} \mathrm{C}$. To do so, net-zero $\mathrm{CO}_{2}$

K.-J. Jung and Y.-C. Ko (corresponding author) are affiliated with the School of Electrical Engineering, Korea University, Seoul 02841, South Korea (E-mail: < kug0860, koyc> @ korea.ac.kr). K.-J. Jung, K.-H. Park, and M.-S Alouini are affiliated with the Computer, Electrical and Mathematical Science and Engineering Division (CEMSE), King Abdullah University of Science and Technology (KAUST), Thuwal, Saudi Arabia (E-mail: <kugjin.jung, kihong.park, slim.alouini >@kaust.edu.sa). emissions on average must be achieved by 2050 [6]. Accordingly, "urgent action to combat climate change" is one of the United Nations Sustainable Development Goals (UNSDGs), for which the continuous increase in greenhouse emissions must be addressed [7]. Hence, the energy consumption of BSs has become not only an economic but also an environmental and social issue. Therefore, powering BSs with renewable energy (RE) such as solar and wind has attracted tremendous interest from industry and academia as a means of reducing both operating expenditures (OPEX) and carbon footprint.

In rural areas such as Sub-Saharan Africa, where nearly half of the BSs do not have access to reliable electrical grids, i.e., off-grid or bad-grid, MNOs resorted to diesel before the design of RE-powered BSs. Similarly, $16 \%$ of BSs in South and Southeast Asia are not connected to reliable electrical grids, and over $80 \%$ of them rely on diesel generators (DGs) [1]. Due to the drawback of using DGs, such as fluctuation in fuel price, $\mathrm{CO}_{2}$ emission, maintenance cost, and lack of subsidies, MNOs have replaced conventional BSs with RE-powered or hybrid counterparts along with both diesel and RE in rural areas. Even for the countries where diesel price is low, REbased systems are cost-effective compared to DGs when the capital expenditure (CAPEX) is amortized. Therefore, nearly 70,000 RE-powered BSs operate worldwide as of 2020, a $45 \%$ increase since 2014 , reducing the annual $\mathrm{CO}_{2}$ e emissions from the DGs of off-grid and bad-grid BSs by 2.2 million metric tons over the last six years [1]. Especially, India has established over 12,000 RE-powered BSs in this period, resulting in the most dramatic reduction in $\mathrm{CO}_{2} \mathrm{e}$ emission.

For the case of academia, research on the energy-efficient design of cellular networks has been conducted for decades in various aspects, including topological management, resource management, and hardware design. Topological management includes BS deployment and operation, whereas resource management involves resource allocation and power control, and the hardware design targets power amplifiers and fanless coolers [8]. With the necessity and feasibility of incorporating RE-based powering unit into cellular network, not only the above research on energy efficiency has been revisited, but also new various communication techniques have been proposed with awareness of RE. In addition, dimensioning and sizing for optimizing energy source in RE-powered BSs have been investigated. These studies are significant for the development of RE-enabled cellular networks since RE highly depends on intermittent and unpredictable weather conditions.

The existing survey works of [9]-[12] address green cellular network which incorporate energy efficiency in their design, components, and protocols. The studies in [9], [10] present research issues to improve the energy efficiency of the cellular network according to their own observation and categories, 


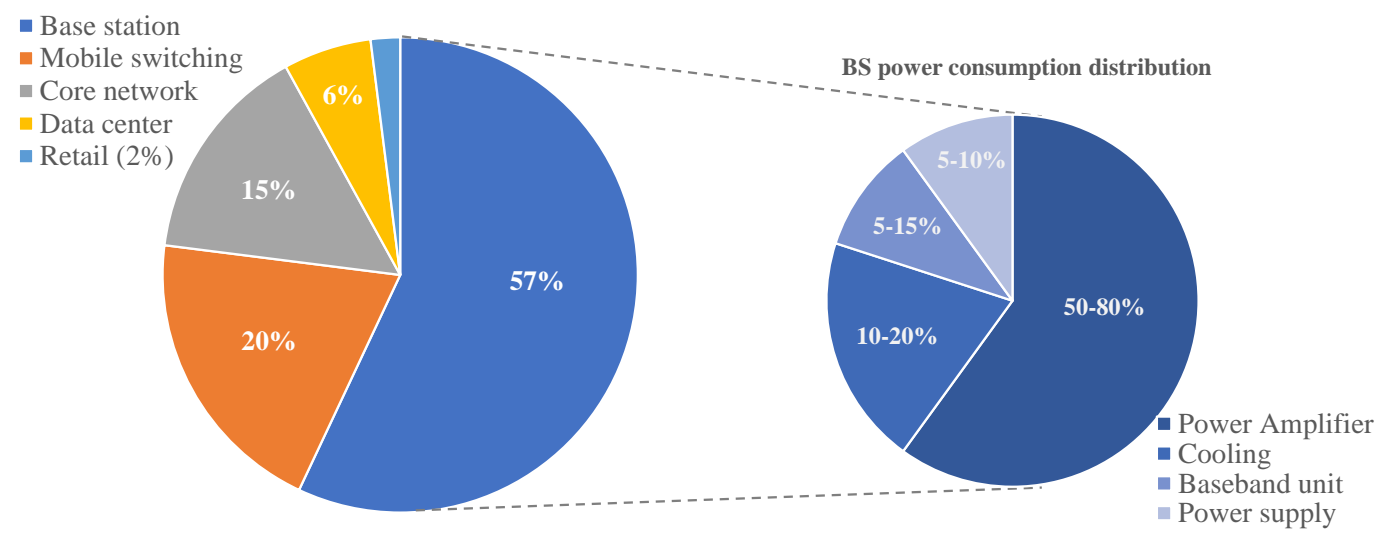

Fig. 1. Power consumption of a wireless cellular network [4].

TABLE I

CELLULAR NETWORK DESIGN ISSUES ADDRESSED IN EXISTING SURVEY WORKS.

\begin{tabular}{|l|c|c|c|c|}
\hline Reference & {$[16]$} & {$[17]$} & {$[18]$} & {$[19]$} \\
\hline Resource management & $\checkmark$ & & & \\
\hline Load balancing (user association) & $\checkmark$ & $\checkmark$ & $\checkmark$ & $\checkmark$ \\
\hline BS on/off strategies & $\checkmark$ & $\checkmark$ & $\checkmark$ & \\
\hline Energy sharing & $\checkmark$ & & & $\checkmark$ \\
\hline Coordinated multipoint (CoMP) & $\checkmark$ & $\checkmark$ & $\checkmark$ & $\checkmark$ \\
\hline Packet scheduling & & $\checkmark$ & & \\
\hline Dimensioning & $\checkmark$ & & & \\
\hline
\end{tabular}

while the work in [11] narrows down the issues to BS sleep mode control. In case of [12], the authors investigated research studies on energy harvesting communications which reduces the dependence on the grid energy. However, these studies introduced the use of RE as one of the strategies for realizing green cellular networks, rather than directly focusing on RE. Therefore, these studies lack content on RE-powered BS.

On the other hand, there have been existing surveys on the RE-powered BS [13]-[19] which can be divided into two groups according to what they focus on. The works of [13]-[15] focused only on the power system of local BSs, rather than the entire cellular network that includes the BSs. Specifically, they do not address design issues or algorithms for cellular networks, which incorporate RE-powered BSs, but rather introduce case studies on BS deployment, feasibility analysis, and the components of the BS power supply system. In addition, since their emphasis is on the BS, the usage of $\mathrm{RE}$ in other parts of a cellular network, such as the aerial base station, network-in-a-box (NIB), and very-small-aperture terminal (VSAT), is not covered.

Other studies of [16]-[19] highlighted potential challenges of incorporating RE-powered BSs into a cellular network and mainly presented cellular network designs and strategies as solutions. The addressed issues in each work are listed in Table I. However, the issues in the tables do not include all the proposed solutions in the literature regarding RE-enabled networks, also they lack systematic classification. Moreover, the related studies were briefly mentioned, and the number of references regarding each issue was remarkably insufficient to thoroughly grasp the topic.
This survey paper is different from the ones mentioned above in that we provide a comprehensive view of both BS power system and networks when incorporating RE-powered BSs into a cellular network. Moreover, unlike the other existing surveys, we introduce RE-enabled cellular network components other than terrestrial BSs, such as the aerial base station, NIB, and VSAT, to cover all the issues related to REenabled networks. This work aims to introduce RE-enabled cellular networks for readers as well as a detailed analysis and classification of the state-of-the-art technologies.

We present an overview of RE-enabled networks in three main sections: i) components in RE-powered BSs and their modelings, ii) design and optimization issues, and iii) feasibility analysis including case studies and other RE-enabled applications in cellular networks. Each one corresponds to Section II, Section III, and Section IV, respectively. In Section II, we highlight the key network components and frequently adopted models which are used for proposing the main strategies or algorithms in the regarding literature. Then, we systematically categorize all the strategies and design issues proposed for implementing RE-enabled networks to provide a good grasp of the topic at a glance in Section III. Section IV introduces the works of feasibility study on RE-powered BSs and usage of RE, especially solar, in an aerial base station, NIB, and VSAT. Finally, we present potential research directions in Section V and conclusions in Section VI.

\section{Components And Models of RE-Powered BS}

The RE-powered BS is composed of energy sources, energy storage system, controller, and BS unit, as shown in Fig. 2. The energy source can be a combinations of a DG and RE such as solar and wind. The harvested energy from the RE sources is delivered to the controller, and the controller determines whether the energy is reserved in the energy storage system or transferred to the BS, depending on network traffic and BS power consumption. The reserved energy can be utilized when there is not enough amount of RE being generated such as at night. 


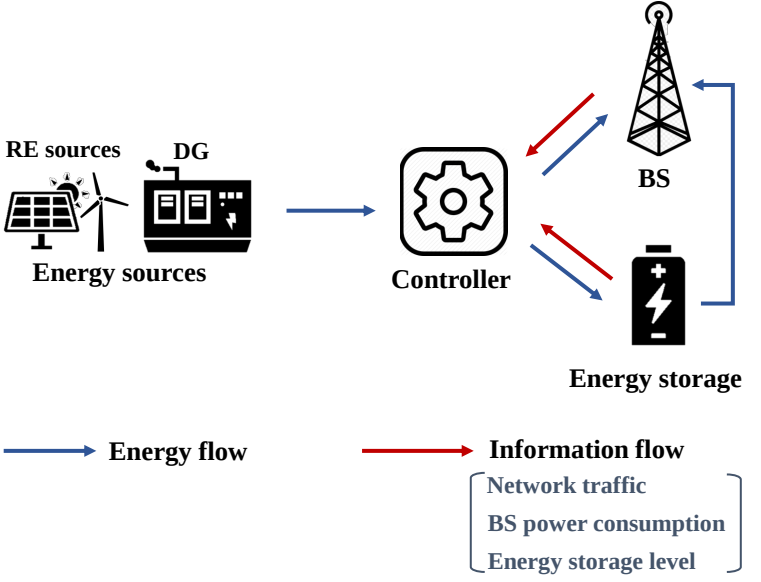

Fig. 2. Components of RE-powered BS.

\section{A. Energy Source}

1) Solar Energy: As an infinite and ubiquitous energy source, solar energy can be collected using photovoltaic (PV) panels, which convert solar irradiation into direct current (DC) electric energy. The generation of solar energy depends on the DC rating of PV panels, tilt of the PV panel, solar irradiation profile, and geographic location [20]. Especially, the irradiation profile and panel location result in temporal and spatial dynamics in the amount of harvested solar energy.

To consider the temporal dynamics, we can divide a day into hourly time slots, i.e., $n=1,2, \ldots, N$, and the harvested solar energy during time slot $n$ in watt can be modeled as $r(n)=$ $\bar{r}(n)+\tilde{r}(n)$, where $\bar{r}(n)$ is the time-varying average solar energy generation, and $\tilde{r}(n)$ is the randomness in RE [21]. The randomness $\tilde{r}(n)$ can be modeled as a zero mean Gaussian random variable, while the average $\bar{r}(n)$ can be expressed as squared exponential function with its maximum value at the peak hour. The maximum value can be calculated as the product of the surface area of the solar PV panel, the peak irradiance, and the energy conversion efficiency [22].

On the other hand, hybrid optimization of multiple energy resources (HOMER) calculates the energy output of the solar PV panel as the product of the rated solar PV array capacity, the peak solar hour, and the solar PV derating factor explaining the degrading effects on PV energy production [23].

Some other studies calculate the net power from the PV panel as the product of the current and voltage of the PV array considering the changes in the current and voltage due to the operating temperature [24].

2) Wind Turbine: Wind is another promising RE since it is available for a long period without diurnal interruption, unlike solar energy. Electric energy is generated by a wind turbine, which is usually used along with solar energy rather than being alone as an energy source. The output power from a wind turbine can be estimated as a quadratic [24] or cubic function [25] of wind velocity.

3) Diesel Generator: In rural areas where many BSs are do not have access to reliable electricity, a back-up power source is needed to provide uninterrupted services. MNOs have resorted to diesel despite its harmful effect on the

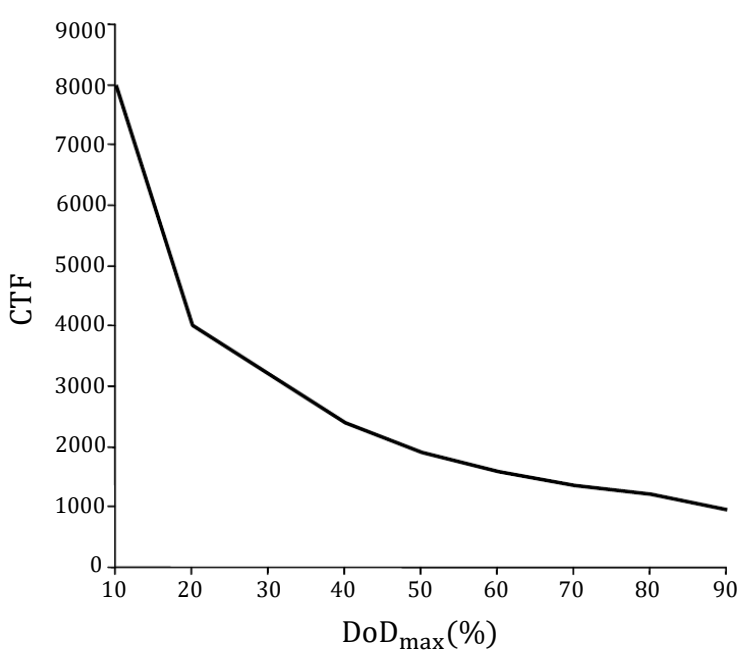

Fig. 3. Relation between CTF and DoD $\max$ [28].

environment and high OPEX, and even for the RE-powered BSs, the DG is considered as a back-up solution. The energy generated by a DG can be calculated as the product of the rated power output, the DG efficiency and the DG running duration [26].

\section{B. Energy Storage System}

One of the major disadvantages of using RE is that the amount of generated energy varies. Moreover, it cannot match the BS load demand profile. The energy storage system can mitigate this problem by storing excess energy and using it on demand. In this way, the energy storage prevents power outages and thus improves the reliability of the BS. The typical energy storage systems are categorized into mechanical, electrical, thermal, and chemical systems. The chemical system is the most commonly used energy storage system, and in this article, we will focus especially on the electro-chemical type, which includes a battery, the hydrogen storage system, and their hybrid systems.

1) Battery: Battery is the most widely used energy storage device that converts stored chemical energy into electrical energy and vice versa. It is modeled based on the state of charge (SoC) which shows the level of battery charge in percentage [24].

On the other hand, the battery depth of discharge (DoD) shows how deeply the battery is discharged by percentage and its maximum value is one of the parameters that explains the battery which is complement to the minimum SoC in percentage. Because the cost of battery accounts for a large proportion of the CAPEX, the lifetime of the battery should be taken into account. Battery life time in years can be calculated by counting charge/discharge cycles to failure (CTF) for each range of DoD for a year [28]. Batteries with a high percentage of maximum DoD are expected to have a short life time since higher maximum DoD leads to a lower value of CTF, as shown in Fig. 3.

The size and type of battery are important factors in designing RE-enabled BSs and determining the duration that BS supports load demand without relying on other energy 
TABLE II

TYPES OF BATTERIES AND THEIR REQUIREMENTS [27]

\begin{tabular}{|c|c|c|c|c|c|c|c|}
\hline Battery type & $\begin{array}{l}\text { Capital cost } \\
(\$ / \mathrm{kWh})\end{array}$ & $\begin{array}{c}\text { Roundtrip } \\
\text { efficiency } \\
(\%)\end{array}$ & $\begin{array}{l}\text { No. of } \\
\text { cycles }\end{array}$ & $\begin{array}{l}\text { Max } \\
\text { DoD } \\
(\%)\end{array}$ & $\begin{array}{c}\text { Operational } \\
\text { temperature } \\
\left({ }^{\circ} \mathrm{C}\right)\end{array}$ & $\begin{array}{l}\text { Energy } \\
\text { density } \\
(\mathrm{Wh} / \mathrm{kg})\end{array}$ & $\begin{array}{c}\text { Operation \& } \\
\text { Maintenance cost }\end{array}$ \\
\hline $\begin{array}{c}\text { Lead-acid } \\
\text { (conventional) }\end{array}$ & $110 \sim 140$ & $75 \sim 85$ & $500 \sim 1000$ & 70 & $-20 \sim 50$ & 30 & Very low \\
\hline $\begin{array}{c}\text { Lead-acid } \\
\text { (OPZS-OPZV) }\end{array}$ & $140 \sim 340$ & $80 \sim 90$ & $1200 \sim 1800$ & 80 & $-20 \sim 50$ & 30 & Very low \\
\hline Nickel-cadmium & $400 \sim 900$ & $70 \sim 80$ & $1500 \sim 3000$ & 100 & $-40 \sim 50$ & 50 & $\approx 0$ \\
\hline Nickel metal hydride & $800 \sim 1200$ & $65 \sim 70$ & $1000 \sim 1500$ & & $-40 \sim 50$ & 80 & $\approx 0$ \\
\hline Lithium ion & $1000 \sim 1700$ & $95 \sim 100$ & $1500 \sim 3000$ & 80 & $-30-90$ & $90 \sim 150$ & $\approx 0$ \\
\hline Lithium polymer & $950 \sim 1650$ & $90 \sim 100$ & 600 & 80 & $-20-60$ & $100-150$ & $\approx 0$ \\
\hline $\begin{array}{l}\text { Sodium sulfur } \\
\quad(\mathrm{NaS})\end{array}$ & $350 \sim 1200$ & $89 \sim 92$ & $2500 \sim 3500$ & 100 & $300 \sim 350$ & 100 & Medium (heating) \\
\hline $\begin{array}{l}\text { Vanadium redox } \\
\text { (VRB) }\end{array}$ & $250 \sim 800$ & $65 \sim 75$ & $5000 \sim 10000$ & 80 & $0 \sim 40$ & $30 \sim 50$ & High (pumps) \\
\hline $\begin{array}{l}\text { Zinc bromine } \\
(\mathrm{ZnBr})\end{array}$ & $300 \sim 950$ & $70 \sim 80$ & 4000 & 100 & $0 \sim 40$ & 70 & High (pumps) \\
\hline Metal air & $50 \sim 250$ & 50 & $100 \sim 500$ & & $-20 \sim 50$ & $450 \sim 650$ & Low \\
\hline
\end{tabular}

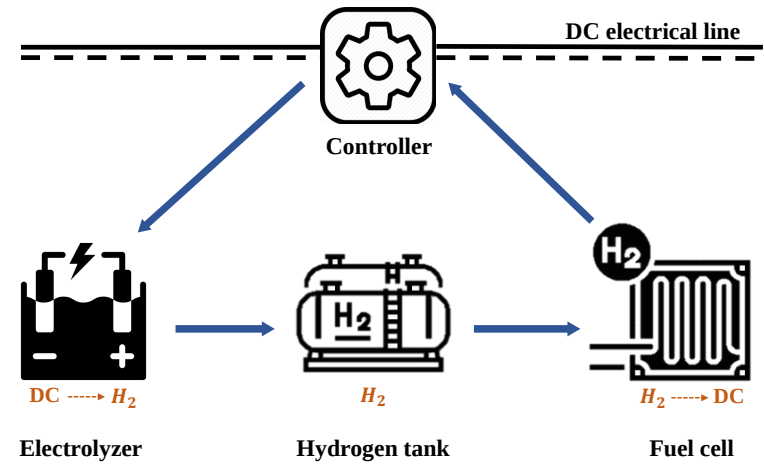

Fig. 4. Hydrogen storage structure [27]

sources. They should be determined under the following system requirements: cost, the number of charge/discharge cycles, operating temperature, and weight [29]. Table II shows the requirements of various battery types used in BSs. Among them, the lead-acid battery is the most widely used for solarpowered BSs due to its low weight, high energy density, high storage efficiency, and low cost, although its disposal is not eco-friendly. In a stand-alone system where BSs are not connected to a power grid, some MNOs choose the new lead-acid battery, OPZS or OPZV, over the conventional one [27]. Even though the lithium-ion battery seems to have many advantages over the lead-acid battery in terms of storage efficiency, the life span of cycles, operating temperature, and energy density, it causes high CAPEX, and the unfavorable effect of deep discharging follows [14]. The sodium-sulfur (NaS) battery is considered to be the most promising one as its capital cost is expected to be reduced to $120 \$ / \mathrm{kWh}$ while its number of cycles can be increased to 5000-6000 cycles [30].

2) Hydrogen Storage: Fuel cell is considered as a feasible option for backup energy in RE-powered BSs and discussed its use in [25], [31], [32] since it stores energy cheaper than conventional batteries and has zero or relatively low gas emission [33]. It consists of an electrolyzer, hydrogen tank, and fuel cell, as shown in Fig. 4 [27]. The electrolyzer decomposes water into hydrogen using excess DC electrical energy and delivers the produced hydrogen to the tank. The hydrogen tank can be used to store chemical energy in hydrogen, and the fuel cell combines hydrogen with oxygen in the air to produce DC electricity. With it, excess energy can be stored in the form of chemical energy, and it can be converted to electrical energy on demand. Moreover, it has the flexibility to store electric energy in the form of a gas or liquid.

A common hydrogen storage system used in the stand-alone BSs is the proton-exchange membrane (PEM) fuel cell since it offers low operating temperature, quick response to changing loads, durability, simplicity in design, robust yield, high energy density, and capability to exploit atmospheric air for energy generation [34], [35].

Although the hydrogen storage system has low-energy storage cost, and offers an environmentally harmless process, and the flexible storage options, it has low round trip efficiency about $30 \%$, while most of the batteries in Table II have above $70 \%$ round trip efficiency, and it costs high CAPEX compared to conventional batteries [27]. This hinders fuel cells to be utilized as a sole energy storage system in stand-alone BSs. Thus, the hybridization of both the battery and hydrogen storage system is utilized for energy storage in solar-powered BSs with a levelized cost of electricity being cheaper than the conventional battery system [34].

\section{BS Power Consumption Model}

The power consumption of BSs increases as the BSs carry a larger amount of traffic load, and it can be modeled using a linear function which increases with the normalized traffic load $K$ in [4]. When the BS is inactive, it only spends sleep-mode power $P_{\text {sleep }}$ in order to save energy. If data traffic arrives, BS is activated with minimum non-zero load power $P_{0}$ to operate $N_{\text {trx }}$ transceiver. In active BS mode, communication power consumption increases linearly by normalized traffic load $K$ with the slope of load-dependent power consumption $\Delta_{p}$ when the output of the power amplifier at the maximum traffic load is $P_{\max }$. The values of parameters for various BS types are listed in Table III.

While many studies considering the BS sleep mode with traffic load exploit the model described above, studies on 
TABLE III

POWER CONSUMPTION FOR DIFFERENT TYPES OF BSS [4].

\begin{tabular}{|c|ccccc|}
\hline BS Type & $N_{\text {TRX }}$ & $P_{\max }[\mathrm{W}]$ & $P_{0}[\mathrm{~W}]$ & $\Delta_{p}$ & $P_{\text {sleep }}[\mathrm{W}]$ \\
\hline Macro & 6 & 20.0 & 130.0 & 4.7 & 75.0 \\
RRH & 6 & 20.0 & 84.0 & 2.8 & 56.0 \\
Micro & 2 & 6.3 & 56.0 & 2.6 & 39.0 \\
Pico & 2 & 0.13 & 6.8 & 4.0 & 4.3 \\
Femto & 2 & 0.05 & 4.8 & 8.0 & 2.9 \\
\hline
\end{tabular}

downlink beamforming express the BS power consumption as the weighted sum of the beamformers' transmitting power, $P_{t}$, and static power, $P_{s}$ [36]-[38]. The transmitting power, $P_{t}$ can be expressed with sum of the squared beamforming vectors. As shown in Fig. 1, the static power includes the cooler, baseband unit, and power supply, which accounts for about $40 \%$ in total, while the transmitting power consumes the remaining $60 \%$ as a power amplifier.

\section{Traffic Model}

In many studies where traffic management, such as user association and load balancing, is addressed or network latency is chosen as a performance metric, traffic load model is proposed and a network latency function is formulated [39][44]. Assuming that the traffic arrives at the BS following an inhomogeneous Poisson point process with arrival rate $\lambda(x)$ and the lengths of files are independently distributed with mean $l(x)$, the average traffic load density of the user can be calculated as the product of them. Then, the traffic load of a BS can be obtained by integrating the average traffic load density of users who are served by the BS. With it, the works in [41], [44] defined the network latency as a quality of service (QoS) metric whereas the studies in [39], [42], [45] introduced the average waiting delays of the users.

\section{E. Energy Harvesting Model}

Regarding RE modeling, some researchers assumed specific energy sources, i.e., solar and wind, and introduced modeling considering their realistic characteristics, as described in Section II.A. In other studies in which the authors did not focus on the energy source, the state of RE in the BS was modeled by assuming either a probability distribution or an uncertainty region since RE generation is unpredictable and intermittent. For the approach of the probability distribution, many studies employed the Poisson counting process to model the time-varying energy arrival times [46]-[50]. For the second approach, the uncertainty set can be postulated from historical measurements and fine forecast techniques. By obtaining the uncertainty set that the harvested energy of each time slot lies in, the uncertain quantities can be modeled. Two different uncertainty sets exist as polyhedral set [37], [51] and ellipsoidal set [37], [52].

\section{F. Types of RE-powered BS}

Even though RE is potentially infinite, its limited availability results in uncertainty about the timing and quantity of energy collected. Thus, BSs are required to be equipped with a reliable

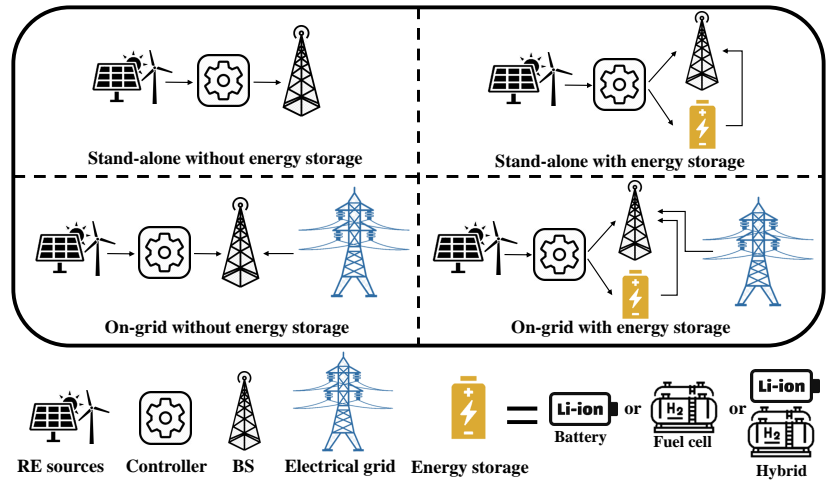

Fig. 5. Types of RE-powered BS.

TABLE IV

TYPES OF BS POWERED BY RE AND THE RELATED WORKS

\begin{tabular}{|c|c|}
\hline Type of BS & References \\
\hline $\begin{array}{c}\text { Stand-alone without } \\
\text { energy storage }\end{array}$ & {$[53]-[55]$} \\
\hline $\begin{array}{c}\text { Stand-alone with } \\
\text { energy storage }\end{array}$ & {$[14],[23],[25],[31],[34],[50],[56]-[77]$} \\
\hline $\begin{array}{c}\text { On-grid without } \\
\text { energy storage }\end{array}$ & {$[38],[40],[42]-[44],[78]-[87]$} \\
\hline $\begin{array}{c}\text { On-grid with } \\
\text { energy storage }\end{array}$ & {$[36],[37],[41],[45],[47],[60]$} \\
\hline
\end{tabular}

energy source, such as a power grid or energy storage system, to provide uninterrupted service for users. In this context, RE-powered BS can be classified according to whether it is connected to a grid (on-grid) or not (stand-alone) and whether it has an energy storage system or not, as depicted in Fig. 5. BS can be either connected to a grid so that it can operate without an outage, or it can be operated solely by RE. On another front, BS can be supported by energy storage described in Section II.B for back-up. Accordingly, four groups can be formed as "stand-alone without energy storage","stand-alone with energy storage"," "on-grid without storage", and "on-grid with energy storage" as shown in Table IV and also the related works are listed. BS can choose its connectivity to a grid and energy storage system with different types of RE sources, i.e., solar, wind, or the hybrid use of both sources.

\section{DESIGN AND OPTIMIZATION IsSUES}

We classify all the design and optimization issues in REenabled networks into five categories: topology adjustment, traffic management, resource management, BS cooperation, and dimensioning. Moreover, each issue has detailed topics as shown in Fig. 6. First, topology explains the issues encountered in the network structure design, such as whether the BS is on and off, where it is deployed, and how to determine the size of each cell. The research on how to allot users' packets into network resources at RE-powered BSs is addressed in traffic management. We investigate the issues of how to efficiently allocate resources in RE, power, temporal, and frequency domains in resource management, and the BS cooperation describes joint signaling and/or powering operation among clustered BSs in a network. Lastly, we investigate the dimensioning of a solar-powered BS, such as sizing the 


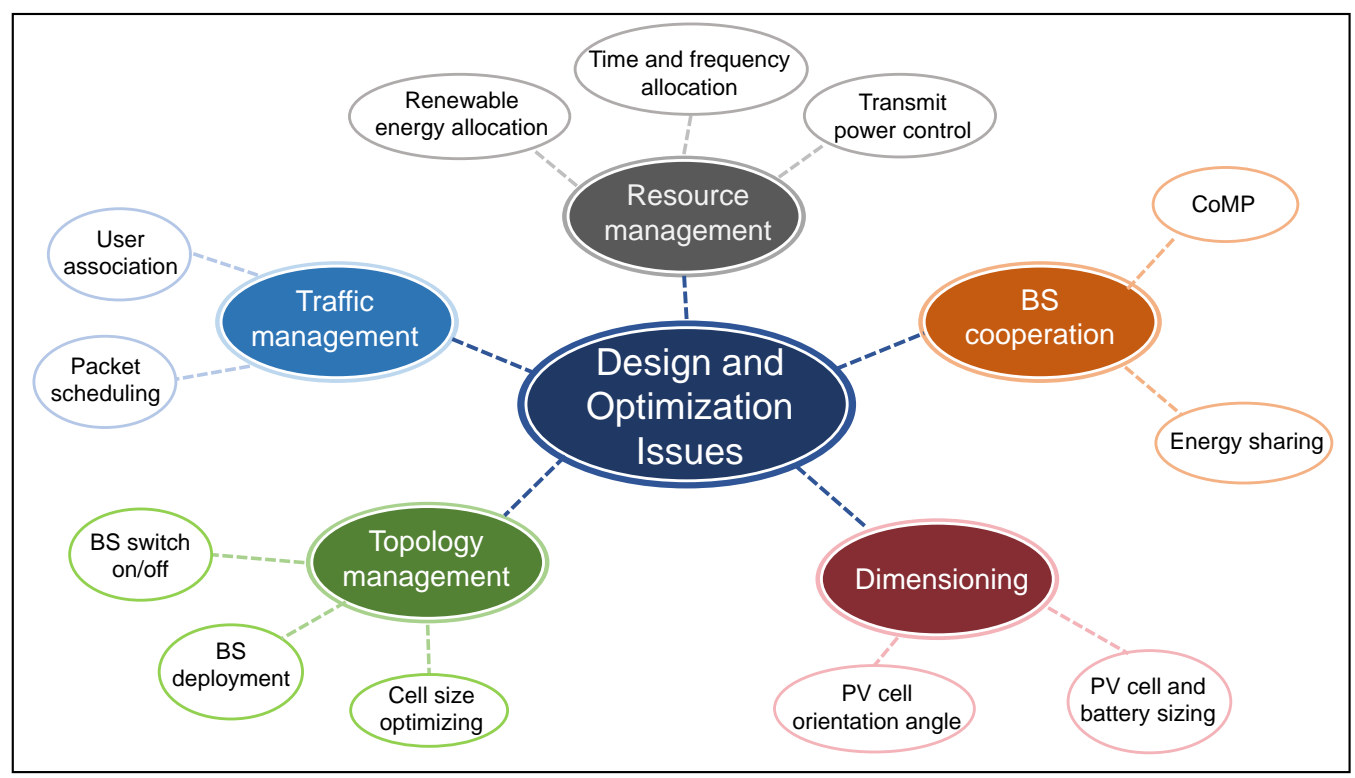

Fig. 6. Design and optimization issues in RE-enabled networks.

PV cell and battery, and adjusting the PV cell angle. Some works adopt one of the five design issues for optimization objectives, while other works address several issues jointly due to their close relation. The detailed design objectives of the categorized network optimization problems are listed in Table V, and the algorithms and methods used to solve the optimization problems are listed in Table VI.

All the issues except for dimensioning have been traditionally investigated without the consideration of RE for enhanced user QoS or energy saving. However, we emphasize that, since the amount of harvested energy varies temporally and spatially, it is necessary to take uncertainty into account in the literature regarding the RE-enabled networks. Considering both the uncertainty of traffic and generated RE, two approaches can be used: offline and online algorithm. For the offline algorithm, energy profile, traffic demand profile, and harvested energy are assumed to be known ahead of time and deterministic as in the works [36], [109]-[111]. On the other hand, since this priori information is limited and unavailable, the online algorithm resorts to only stochastic knowledge and casual information obtained through learning algorithms [37], [76], [90], [91], [93], [101], [107], [108]. Some works considered both algorithms and compared them [47], [54], [89], [100], [112].

\section{A. Topology Management}

1) BS Deployment: By properly deploying the BSs considering traffic load demands, the network operator can reduce CAPEX and OPEX in the context of energy consumption while maintaining service quality of the users. For the case of BS powered by RE, the BS deployment problem has been addressed in [125]-[127]. Since the initial cost of harnessing $\mathrm{RE}$ is expensive, researchers have minimized the number of deployed BSs under user QoS constraint [125], whereas power consumption was minimized by efficiently deploying the BSs
[126]. Both CAPEX and OPEX were addressed in [127] by introducing the weighted sum of the total installation cost and grid power consumption as a minimizing objective function. In addition to the deployment of BSs, the study in [127] assumed that BSs can have dedicated power line connections from other RE sources and determined the inter connectivity among RE sources and dealt with traffic load assignment problems.

2) BS Switch On/off: Since traffic demand tends to fluctuate and networks are dimensioned and operated based on the peak hour traffic, it can be inefficient in terms of energy consumption to operate all BSs in the network during off-peak hours. Moreover, a case study in Manchester, United Kingdom, based on the real temporal traffic trace over one week reveals that, during weekdays, the traffic is $10 \%$ less than its peak value for $30 \%$ of the time, whereas the time portion increases during weekends [128]. This motivates researchers to consider turning off some underutilized BSs and let the remaining active BSs be responsible for the service and coverage of networks for a certain period when the traffic demand is lower than a certain level. Considering RE-enabled networks, BS switching can be adopted by obtaining the optimal parameters for the switch on/off strategy [123], or adjusting the BSs' on/off state for each time slot [113], [114], or finding the optimal set of active BSs on a longer time scale [40], [106]. To be specific about the optimal set of active BSs, it is jointly considered with user association [40] or energy scheduling [106]. Here the time-scale of the BS switching is assumed to be larger than that of the user association or energy scheduling so that each problem can be dealt with separately.

For each work in more detail, D. Niyato et al. [123] investigated the performance of a solar-powered wireless sensor/mesh network in terms of packet blocking and dropping probabilities with the presented queuing model. Given the fact that as the period of BS's off state increases, the packet blocking probability also increases while the packet dropping 
TABLE V

OBJECTIVE FUNCTIONS WITH DESIGN AND OPERATIONAL STRATEGIES FOR RE-POWERED BSS IN NETWORKS

\begin{tabular}{|c|c|c|c|c|c|}
\hline \multirow{2}{*}{ Objective function } & \multicolumn{5}{|c|}{ Strategies } \\
\hline & Topology management & Traffic management & Resource management & BS cooperation & Dimensioning \\
\hline $\begin{array}{l}\text { Minimizing } \\
\text { the on-grid energy consumption }\end{array}$ & [95], [113], [114] & $\begin{array}{c}\text { [82], [100], [102] } \\
{[103],[115]}\end{array}$ & $\begin{array}{c}{[84],[95],[100],[103]} \\
{[107],[114]}\end{array}$ & $\begin{array}{c}{[38],[79]-[81]} \\
{[84],[88],[89]} \\
{[107]} \\
{[116],[117]}\end{array}$ & \\
\hline $\begin{array}{l}\text { Minimizing the total energy } \\
\text { (on-grid and RE) cost }\end{array}$ & & & & [118] & \\
\hline $\begin{array}{c}\text { Minimizing } \\
\text { the net energy cost in smart grid }\end{array}$ & & & & [21] & \\
\hline $\begin{array}{c}\text { Maximizing } \\
\text { the network utility }\end{array}$ & & [55], [99], [101] & [76], [99] & [76] & \\
\hline $\begin{array}{l}\text { Minimizing } \\
\text { the network latency }\end{array}$ & & [39], [85] & [57], [58] & & \\
\hline $\begin{array}{l}\text { Maximizing the weighted } \\
\text { sum of on-grid consumption } \\
\text { and user QoS metric }\end{array}$ & [40] & $\begin{array}{c}{[40],[41]} \\
{[42]-[44]} \\
{[86],[87],[108]}\end{array}$ & [41], [108] & & \\
\hline $\begin{array}{c}\text { Maximizing } \\
\text { the utilization of RE }\end{array}$ & [104] & [82], [104] & & & \\
\hline $\begin{array}{c}\text { Maximizing } \\
\text { the energy efficiency }\end{array}$ & & [96], [105] & [47], [105] & & \\
\hline $\begin{array}{c}\text { Minimizing } \\
\text { the cost of using } \\
\text { conventional energy source }\end{array}$ & [106] & & [83], [93] & [36], [37], [91] & [65] \\
\hline $\begin{array}{c}\text { Maximizing } \\
\text { the profit of network operator }\end{array}$ & & [94] & [83] & [94] & \\
\hline $\begin{array}{c}\text { Maximizing } \\
\text { the weighted sum rate }\end{array}$ & & & & [78], [119] & \\
\hline $\begin{array}{l}\text { Minimizing } \\
\text { the capital cost }\end{array}$ & & & & & $\begin{array}{c}{[45],[60]} \\
{[63],[66]} \\
{[120]-[122]}\end{array}$ \\
\hline $\begin{array}{c}\text { Maximizing } \\
\text { the number of accepted users }\end{array}$ & & [54] & & & \\
\hline $\begin{array}{c}\text { Minimizing } \\
\text { the transmission completion time }\end{array}$ & & [109]-[111] & & & \\
\hline
\end{tabular}

probability decreases, they obtained the optimal probability of switching on and off considering the trade-off between packet blocking and packet dropping probabilities.

J. Gong et al. [113] obtained the optimal BSs' on/off state for each time slot to minimize the time average of grid power consumption under the blocking probability constraint as QoS metric. Moreover, the authors extended the work by introducing the opportunistic sleep mode of BS where an active BS turns into the sleep mode with a time ratio by turning off some subframes [114]. With it, the optimal sleep ratio and the optimal number of active subcarriers were obtained along with the optimal BSs' on/off state.

As mentioned above, the work described in [106] optimized energy scheduling with the optimal amount of supply energy from the power grid, distributed local generator, and battery for each time slot along with the optimal on/off state for each frame with multiple time slots. All the optimization variables aimed to minimize the energy cost from the power grid and local generator.

The weighted sum of energy consumption and network flow-level performance was minimized in heterogeneous networks (HetNets) by solving two subproblems [40]: BS switch on/off operation and user association. The weight parameter determines the trade-off between energy consumption and user QoS.

3) Cell Size Optimization: Cell size is one of the factors that determines the energy consumption of the BS in that it

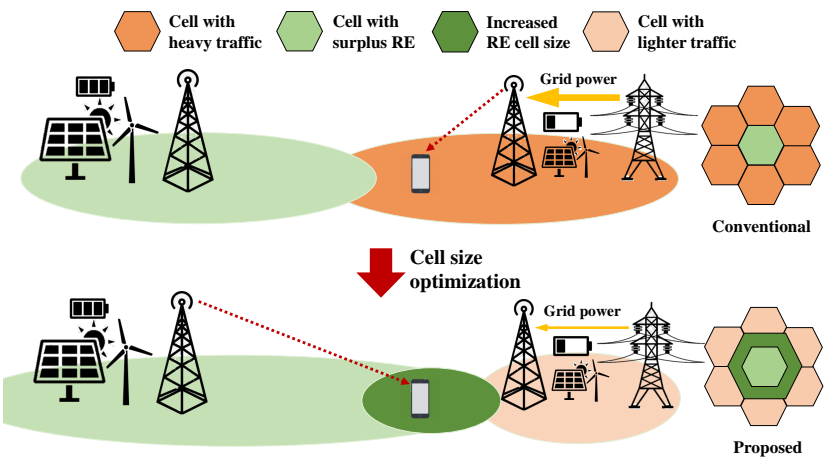

Fig. 7. Cell size control increasing the cell with surplus RE and inducing less grid energy consumption in RE-enabled networks [129].

offloads mobile traffic, especially at the cell edge. With the RE-powered BS in mind, increasing the cell size of BSs with surplus RE while shrinking the cell size of neighbor BSs, as shown in Fig. 7, can minimize on-grid energy [95] or maximize RE utilization [104], [129].

In [95], T. Han et al. formulated two subproblems, i.e., RE allocation and cell size optimization, and proposed algorithm for each problem to deal with the temporal and spatial randomness of the harvested $\mathrm{RE}$ and the mobile traffic load. The first subproblem aims to minimize on-grid energy consumption allocating $\mathrm{RE}$ to the $\mathrm{BS}$ in the time domain, and 
TABLE VI

ALGORITHMS AND METHODS

\begin{tabular}{|c|c|c|}
\hline Strategies & References & Algorithms and methods \\
\hline \multirow[t]{3}{*}{ BS switch on/off } & [123] & $\begin{array}{l}\text { - Game theory formulation } \\
\text { - Direct search method } \\
\text { - Pattern search method }\end{array}$ \\
\hline & [113], [114] & - Dynamic programming \\
\hline & [106] & $\begin{array}{l}\text { - Lyapunov optimization tech- } \\
\text { nique }\end{array}$ \\
\hline $\begin{array}{l}\text { Packet } \\
\text { scheduling }\end{array}$ & [111] & $\begin{array}{l}\text { - Sequential unconstrained } \\
\text { minimization technique }\end{array}$ \\
\hline \multirow[t]{2}{*}{ User association } & [101] & $\begin{array}{l}\text { - Lagrange dual decomposi- } \\
\text { tion method }\end{array}$ \\
\hline & [8] & - Greedy algorithm \\
\hline \multirow{3}{*}{$\begin{array}{l}\text { Transmit } \\
\text { power control }\end{array}$} & [99] & $\begin{array}{l}\text { - Alternating direction method } \\
\text { of multipliers }\end{array}$ \\
\hline & [93], [108] & $\begin{array}{l}\text { - Lyapunov optimization tech- } \\
\text { nique }\end{array}$ \\
\hline & [96] & $\begin{array}{l}\text { - Mesh adaptive direct search } \\
\text { algorithm }\end{array}$ \\
\hline \multirow{3}{*}{ CoMP } & [36] & - Dual subgradient method \\
\hline & [37] & $\begin{array}{l}\text { - Dual subgradient method } \\
\text { - Lyapunov optimization tech- } \\
\text { nique }\end{array}$ \\
\hline & [78] & - Ellipsoid method \\
\hline \multirow{4}{*}{ Energy sharing } & [89] & - Greedy algorithm \\
\hline & [76] & $\begin{array}{l}\text { - Lyapunov optimization tech- } \\
\text { nique }\end{array}$ \\
\hline & [117] & - Subgradient method \\
\hline & [84] & - Univariate search method \\
\hline $\begin{array}{l}\text { PV cell and bat- } \\
\text { tery sizing }\end{array}$ & [60] & - Genetic algorithm \\
\hline PV cell angle & [124] & $\begin{array}{l}\text { - Simplex algorithm } \\
\text { - Branch and bound algorithm }\end{array}$ \\
\hline
\end{tabular}

based on the solution, the second one minimizes the ratio of energy consumption to allocated RE for each BS with the optimal cell size by adjusting the pilot signal power of each BS. Specifically, the second algorithm increases cell size of a BS with sufficient amount of RE to balance the energy consumption among BSs.

The work in [129] introduces two basic approaches to guide more power consumption into the BS with excess RE. The first approach is tuning the handover parameter so that users at the cell edge would have preferential access to the BS with extra RE. The second approach is done by increasing the downlink transmission power of the BS with extra RE while the neighboring BSs reduce their power. [104] proposes an algorithm that adjusts cell size by determining the vector of the beacon power level for the BS so that the utilization of RE can be maximized by minimizing the energy depleting rate.

\section{B. Traffic Management}

1) Packet Scheduling: Energy-efficient packet scheduling over a fading channel with data arrival and deadline constraint has been extensively investigated. Energy harvesting from ambient energy sources has been incorporated, as shown in Fig. 8. Accordingly, the arrivals of the harvested energy have been added as a factor to consider. Related studies focused

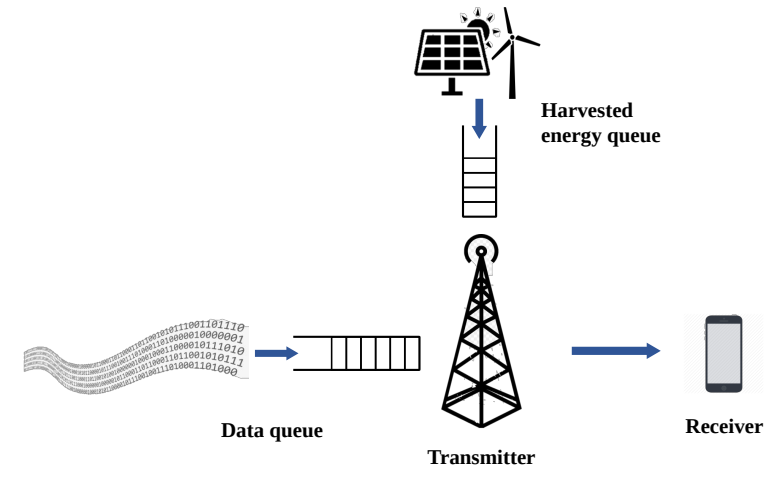

Fig. 8. Packet scheduling with energy harvesting [109].

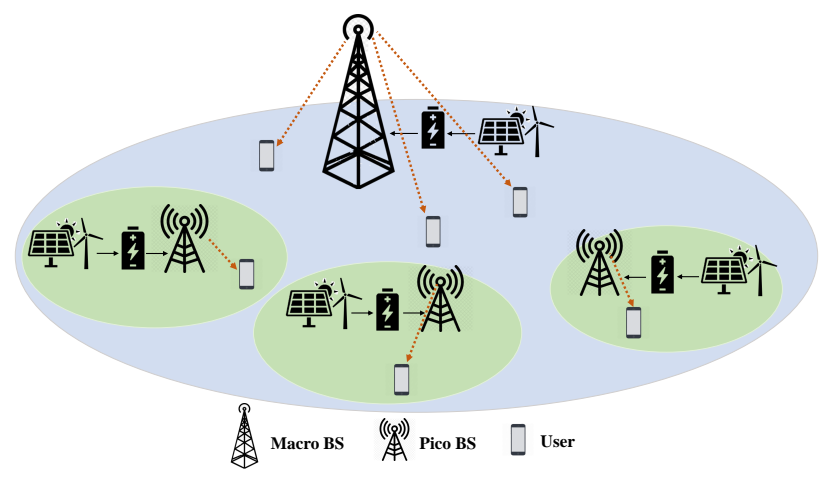

Fig. 9. User association in HetNets with RE.

on transmission methods, not on how energy is harvested [109]-[111]. It was assumed that the transmitter has the knowledge of energy harvesting as well as the channel state leading to offline algorithm. The trade-off between the energy harvesting time and the packet transmission time was considered using the causality constraint of packets and harvested energy. Shorter packet transmission time requires more harvested energy, which is limited. Based on this limitation, the optimal transmission rate and power were determined to minimize the overall transmission completion time in different situations. The transmission time minimization was formulated on AWGN channel in [109] while authors [110] extended it to AWGN broadcast channel with a static data pool. Furthermore, fading channel was considered [111]. The solution adjusts the transmission rate and power not only according to packet arrivals and harvested energy but also according to the channel state.

Some studies maximized the utilization of RE to minimize the conventional energy consumption, rather than minimizing the transmission completion time [82], [115]. For example, the authors balanced the energy consumption of a BS among time slots by packet scheduling under packet delivery time constraints, and then allocated the bandwidth to minimize the energy consumption of the BS [115]. Moreover, the work described in [82] scheduled the users first, and obtained the optimal number of packets allocated for each user and time slot.

2) User Association: The energy consumption of a BS depends on its traffic load, and MNOs can save operating 
costs by directing traffic loads to the BSs with higher RE capacity. The conventional received signal strength-based user association leads to a severe traffic load imbalance among macro BSs and small-cell BSs due to the spatial dynamics of BSs deployment and the disparities of transmit powers and BS capabilities. Then, the QoS of associated users may not be met in overloaded BSs, while the resources may not be fully utilized in lightly loaded BSs.

In HetNet where small cells are densely deployed in a macro-cellular networks to achieve spectrum and energy efficiency, small BSs require smaller transmit power and operational power than the macro BSs. This enables HetNets to be easily combined with an RE source, whether it be the only energy source or the additional energy source along with on-grid energy, as shown in Fig. 9, since RE shows high variability and may not be sufficient to supply high-power to macro BSs [50]. In this case, even the user association based on cell traffic load is undesirable in terms of on-grid energy consumption; that is, some BSs drain their available $\mathrm{RE}$ and must pull energy from the on-grid energy, while others have excess RE with less energy demand. In this context, user association considering on-grid energy consumption and addressing the unbalanced work load distribution issue among BSs in HetNets with RE sources has been intensively studied.

Some studies addressed user association along with resource allocation, such as bandwidth [130], RE source [100], [103], transmit power [99], and time/frequency resources [101]. In [130], the on-grid power consumption was minimized along with the minimum user minimum signal to interference \& noise ratio (SINR) constraint. Additionally, two suboptimization problems were proposed for minimizing on-grid energy consumption in time and spatial domains [100], [103]. The authors optimized the user association in a certain time slot and then, obtained the optimal RE allocation across different time slots. In [99], [101], the authors defined the utility function using their own functions and maximized it. The utility function in [99] considers users' throughput, the cost for using the radio resources, the cost of using the backhaul resource, and the saving on using caching while that in [101] is formulated as the sum of the logarithm of user's rate to balance network performance and user fairness. The maximization of utility proportional fairness in [101] can also be found in [55].

Several studies jointly optimized on-grid energy consumption and one of the various user QoS metrics, such as the effective data rate [43], [86], traffic delay [41], [42], [44], packet drop cost [108], and flow level performance [8], [40] by formulating the objective function as the weighted sum of the user QoS function and on-grid energy consumption. By linearly combining the two competing functions with the weighting coefficient, the two objectives can be simultaneously handled with flexible tradeoff considering preferences or importance. Users' throughput was used as the QoS metric in [43], [86]. The authors defined the effective data rate of a user's flow and formulated a maximization problem by combining it with the on-grid energy consumption.

Average delay was considered as a user QoS metric, thus the minimization problem was formulated and each work defined its own cost function of average delay and on-grid energy consumption [41], [42], [44]. Especially, the work in [44] considered 3-tier HetNets where not only macro BSs and pico BSs took parts but also relay stations forwarded data received from macro BSs to users and vice versa. The optimal traffic load was obtained not only for the BSs but also for the relay stations. Similarly, the study in [87] also formulated the weighted sum of the cost of average traffic delay and cost of energy consumption, but contrary to [41], [42], [44], it considered uplink as well as downlink, thus formulating the objective function based on the weighted sum of the average traffic delay, the downlink on-grid energy consumption, and the uplink energy consumption of users. In [108], the minimization objective function included packet drop cost as the user QoS metric, which represented the QoS parameter as the percentage of successfully transmitted data packets of the users. Unlike works that address the optimization through only user association [42], [44], [87], optimal user association and optimal BS downlink transmission power control were achieved in [41], [108].

In [8], [40], user association and BS switch on/off operation were addressed simultaneously to minimize the weighted sum of flow level performance and on-grid energy consumption by determining the optimal set of active BSs and user association. The work in [8] introduced general models for BS power consumption and flow level performance, i.e., throughput, and traffic delay. The problem was decomposed into two subproblems: BS switch on/off and user association based on time scale separation. However, the authors in [8] did not consider RE in powering BSs and the work was expanded in [40] by addressing HetNets with RE and applying on-grid energy consumption.

Other than the weighted sum of two competing functions, other objective functions were also considered for the optimal user association for BSs in HetNets with RE and on-grid energy by minimizing on-gird power consumption [102]; and minimizing the sum of the weighted latency [39], [85].

Moreover, studies were conducted on user association in HetNets with BSs solely powered by RE supply [54], [55], [74], [96] as opposed to the above works with RE and on-grid. While these works did not include on-grid energy consumption in their objective functions and constraints, they aimed to i) maximize the number of accepted users and minimize the required bandwidth resource [54] or ii) maximize the logarithm of users' rate [55] or iii) maximize the topology potential, which is defined to measure the desirability of association between BSs and users [74] or iv) maximize energy efficiency, which is defined as the ratio of the total data rate to the total power consumption [96].

\section{Resource Management}

We cover RE allocation, time and frequency allocation, and transmit power control in resource management. By exploiting these resources efficiently, the objective functions mentioned in Table $\mathrm{V}$ can reach optimal performance, and accordingly, many studies have dealt with the efficient utilization of resources. Through the regarding literature, it could be found 


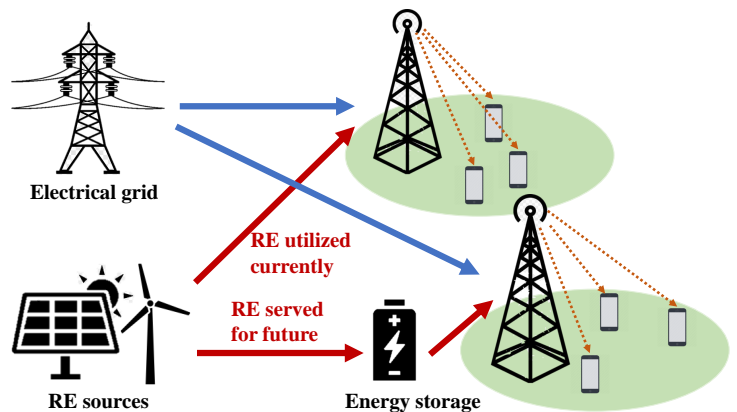

Fig. 10. RE allocation across time slots by determining the amount of RE utilized at current state and reserved for the future.

that the resource management was usually addressed with other schemes, such as BS switch on/off, energy sharing, cell size optimization, and user association rather than being addressed alone.

1) Renewable Energy Allocation: The energy storage system is one of the solutions for enduring the intermittent generation of RE sources in RE-enabled networks. The stored energy can be used efficiently to improve the performance with the optimal amount of RE that should be utilized at the current stage and reserved for the future, as shown in Fig. 10. This RE allocation across time slots has been addressed jointly with energy sharing [94], user association [100], [103], cell size optimization [95], and transmit power control [57], [58].

The authors [94] aimed to maximize the profit of a network operator using the optimal amount of energy drawn from a smart grid, and RE generator for each BS and each time slot considering the uncertainty of RE and the variation in the smart grid price. Additionally, since the network is powered by the smart grid, the authors optimized the amount of excess $\mathrm{RE}$ to be sold back to the smart grid and included it in the profit.

Because the amount of harvested RE and the mobile traffic load exhibited randomness both in time and space, the on-grid energy consumption can be minimized in two dimensions by formulating two subproblems in which each one corresponds to time and space, respectively: the time dimension for RE allocation across time slot and space dimension for user association [100], [103] or cell size optimization [95].

In [57], V. Chamola et al. proposed a scheme which allocates available $\mathrm{RE}$ in proportion to the $\mathrm{BS}$ load for a network of stand-alone solar-powered BSs. Given the energy allocation, the network latency was minimized with optimal BS downlink transmit power control under the constrained energy availability at the BSs. This work was extended by adding user association problem which determines the optimal BS loads given RE allocation and power control [58]. The results were validated using a real BS deployment scenario from United Kingdom and compared with existing algorithms in terms of reducing energy outages with network latency performance.

2) Time and Frequency Allocation: Provided that the REpowered BSs schedule transmission over time or frequency slot, the time and frequency can be allocated as resources. The related works addressed it simultaneously with BS switch on/off [114], transmit power control [47], [84], energy sharing [84], and user association [84], [101].

In [114], the proposed algorithm determines BSs' on-off states and the number of active subcarriers allocated to each $\mathrm{BS}$ to adjust the power consumption of BS considering the traffic load and amount of harvested RE. The joint optimization minimizes the average grid power consumption to the extent that new users are not blocked by adopting the blocking probability as the QoS metric. In [84], the authors took into account the energy sharing among BSs, meaning that transferred energy needs to be included in minimizing the grid energy cost. Other than energy sharing, the ratio of time and frequency resources, transmission power, and user association were jointly optimized. Unlike other studies, the work in [47] classified the transmit power according to the drawn power source, e.g., RE or non-RE, and whether the power was consumed for signal transmission or processing. The classified power was then optimized for maximizing the weighted energy efficiency along with the subchannel allocation in an orthogonal frequency division multiple access (OFDMA) downlink network.

3) Transmit Power Control: In RE-powered BS during downlink transmission, the transmit power can be one of the resource design variables to be considered along with user association [41], [96], [99], [105], [108], energy sharing [76], [107], and battery management [93]. Although the optimization variables handled by some studies were the same, they differed depending on what objective functions and constraints were assumed and how the system model was constructed.

For the cases dealing with the transmit power control with user association in the network powered by both grid and $\mathrm{RE}$, maximizing the energy efficiency was addressed in the case of multiple-input multiple-output (MIMO) and full duplex [105] and heterogeneous cloud radio access network (CRAN) [96]. In addition, [99] maximized a self-defined utility function which takes into account user's throughput, the cost of using resources, and saving by using caching, while the study in [41] investigated the trade-off between grid energy saving and network latency to minimize their weighted sum as an objective function. In [108], the authors minimized network service cost, which includes grid energy consumption and achievable QoS in terms of packet drop probability.

To deal with the cases that consider energy sharing with power control, they optimized the transmitted power along with the amount of energy transferred between BSs across time slots. The authors [107] minimized on-grid energy consumption under the consideration of stochastic user arrival, traffic arrival, the amount of harvested RE, and queuing of traffic and energy while guaranteeing the minimum average user throughput. The work in [76] maximized the time-averaged network utility defined as the transmitted data of the whole network in a millimeter-wave (mmWave) cellular network while ensuring the packet queue length was bounded. The BSs in [76] were solely powered by RE, whereas the BSs in [107] were supported by a grid.

Lastly, for the case of power control with battery man- 


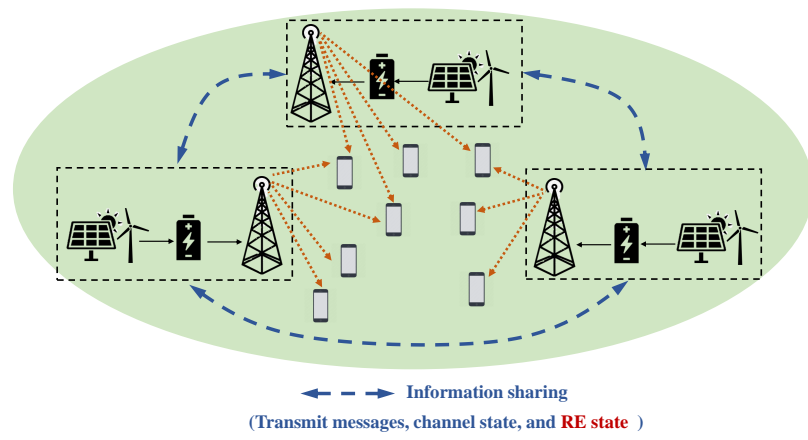

Fig. 11. CoMP system with RE-based BSs, where the BSs share not only communication information such as the transmit messages and the channel state, but also the amount of harvested RE of each BS.

agement, the amounts of charged power and transmit power were jointly determined in [93]. The authors investigated the problem of minimizing the electricity cost of BSs assuming a real-time electricity market where the price of grid energy varies over time.

\section{BS Cooperation}

1) Coordinated multipoint (CoMP): In a network where inter-cell interference is severe due to close proximity among BSs, such as HetNets, CoMP is a promising solution to alleviate the interference. In a CoMP system, BSs form clusters, and share their transmit messages and channel state information to mitigate inter-cell interference with coordinated beamforming. It enables BSs to transform the interference into desired signals and utilize the distributed multiple antennas. In this way, the transmit power of BSs can be compensated by each other, and the user service quality in the network can be improved with the reduced signalling cost.

CoMP can offer a solution for harvested energy variations in BSs by including the RE state of each BS into the shared information among BSs as shown in Fig. 11 [19]. The increased energy consumption due to the duplicate transmissions of the CoMP is another reason that the studies have considered CoMP with RE-based BSs. Also, BSs with energy harvesting may need to sleep during charging, leading to frequent handovers. The CoMP can be a promising solution by alleviating the outages, thus improving the reliability of communication. In most of the works that considered CoMP with RE-enabled networks, the optimal beamforming vector was investigated [36], [37], [78], [79] or the optimal subset of BSs was obtained for cluster formation [80], [81], or both [38].

In the work with the optimal beamforming vector, each BS was equipped with not only an RE generator, but also a twoway trading smart grid system, which enables energy sharing among BSs [36], [37], [78], [79]. Accordingly, the exchanged energy was optimized along with the optimal cooperative downlink beamforming vectors based on the shared information. Xin Wang et al. defined the transaction cost of BS for each time slot as a linear combination of surplus electricity and deficit electricity and minimize the transaction cost subject to the worst-case SINR [36], [37]. In the work of [36], the authors

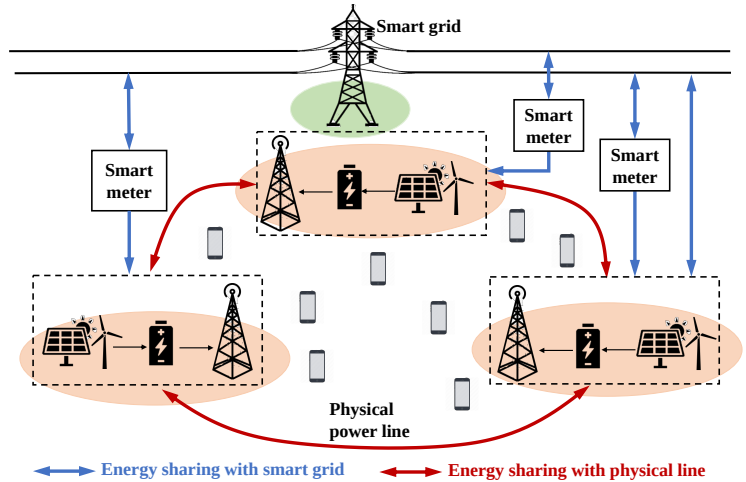

Fig. 12. Direct wired energy sharing among BSs which includes both smart grid trading and transmission through physical line.

considered the worst-case energy transaction cost over a given finite horizon with offline algorithm assuming RE source is known ahead of time. However, since the offline algorithm had high computational complexity in large time horizon, the authors considered online algorithm and formulated the timeaverage energy transaction cost over infinite time horizon in the work of [37]. In [78], Jie $\mathrm{Xu}$ et al. also jointly optimized the beamforming vectors and the exchanged power, but they specifically obtained the optimal transmit power allocation of zero-forcing ( $\mathrm{ZF}$ ) precoding at the BSs to maximize the weighted sum rate. The optimal result proved the need for energy sharing in CoMP schemes to fully utilize the harvested RE. The same authors minimized the total grid energy cost with the optimal amount of purchased/sold energy from/to the grid and the optimal transmit beamforming vectors while satisfying the user's minimum SINR requirement in [79]. The results showed performance gain compared to separate design of energy trading and beamforming vector.

The works in [80], [81] also obtained the optimal subset of BSs in HetNets by assigning BSs for each user and minimized the grid energy consumption. Further, the authors combined the cooperative transmission with the sleep mode of the BS in [80]. The RE-aware CRAN was combined with CoMP [38] so that the decoupled remote radio heads (RRHs) can be densely deployed and cooperatively transmit the data to the served user. The authors obtained the optimal beamforming vector and the subsets of active RRHs for minimizing the grid energy consumption, subject to the minimum SINR constraint.

The work in [46] considered an uplink transmission of Internet of Things with two energy harvesting BSs, which is prone to outage due to handover and BS sleeping during recharging. As a solution, the authors proposed CoMP and analyzed the performance in terms of outage probability and ergodic capacity.

2) Energy Sharing: Energy sharing has been newly suggested and investigated as a solution to the energy imbalance between BSs due to the randomness in both RE generation and mobile traffic at each BS. In other words, the energy surplus and short fall of BSs can average out by exchanging the energy among BSs. The energy sharing mechanism can be classified as shown in Table VII [131]. In contrast with direct energy sharing, traffic offloading, which gives more traffic 
TABLE VII

ENERGY SHARING CLASSIFICATION [131].

\begin{tabular}{|c|c|c|c|c|c|}
\hline \multirow{3}{*}{$\begin{array}{l}\text { Energy sharing } \\
\text { mechanism }\end{array}$} & \multicolumn{3}{|c|}{ Direct energy sharing } & \multicolumn{2}{|c|}{ Non-direct energy sharing } \\
\hline & \multicolumn{2}{|c|}{ Wired energy sharing } & \multirow{2}{*}{ Wireless energy sharing } & \multirow{2}{*}{$\begin{array}{c}\text { Traffic offloading } \\
\text { (III-B2. User association) }\end{array}$} & \multirow{2}{*}{$\begin{array}{l}\text { Cooperative transmission } \\
\text { (III-D1. CoMP) }\end{array}$} \\
\hline & Physical power line & Smart grid & & & \\
\hline References & $\begin{array}{c}{[21],[89],[107]} \\
{[116],[118]}\end{array}$ & $\begin{array}{c}{[21],[36],[37]} \\
{[76],[78],[79]} \\
{[84],[94],[117]}\end{array}$ & * & [84], [117] & [36], [37], [78], [79] \\
\hline
\end{tabular}

*Wireless power transfer is not suitable for energy sharing among RE-powered BSs.

load to BSs with surplus energy, is regarded as non-direct energy sharing. Also, cooperative transmission can be a way of non-direct energy sharing since it controls energy availability by leveraging underutilized energy among BSs. We describe traffic offloading and cooperative transmission in the form of user association in the traffic management section and CoMP in the BS cooperation section, respectively.

In direct energy sharing, most researchers dealt with the energy imbalance problem among RE-powered BSs and chose wired energy sharing over wireless energy sharing. Although energy can be shared through wireless power transfer, it is limited to short distances due to its high power losses and not suitable for energy sharing between BSs [132]. As shown in Fig. 12, the direct wired energy sharing can be realized by physical power transmission lines among BSs and the twoway power flow enabled smart grid. The works addressing each energy sharing mechanism are listed in Table VII and the mechanisms can be considered jointly as physical power line and smart grid [21], smart grid and user association [84], [117], and smart grid and CoMP [36], [37], [78], [79].

Power sharing via the direct power line entails deploying physical power transmission lines among sharing BSs. It leads to high CAPEX, while trading through smart grids costs OPEX that must be paid to the grid operator. The regarding works determine the amount of wired energy transaction among the BSs or between BS and smart grid or both. With the optimal amount, grid power consumption can be minimized [89], [107], [116], [117]. In the case of energy sharing through physical power line between two BSs, it was shown that $80 \%$ of grid power consumption can be saved [89]. However, this result is limited to a simple topology of the cellular network since it considered only two BSs. More complicate topology was considered with $N$ BSs connected to smart grid and the amount of energy transferred through the smart grid was optimized along with traffic offloading [117]. Nevertheless, the work did not consider the distance between two BSs which affects power losses. Considering the topology of the cellular network, D. Benda et al. proposed two algorithms and compared their results [116]. First one was aware of the distance-dependent power loss in the transmission line and the other one was not. Their results showed that the first algorithm saved $30 \%$ more grid power in a fully connected cellular network with 15 BSs by searching for shorter distances among BSs. The energy sharing through power line was addressed along with optimal resource allocation such as subchannel and power in [107]. Although the work was limited to the case of two BSs connected to each other, its result showed that combination of energy sharing and resource allocation

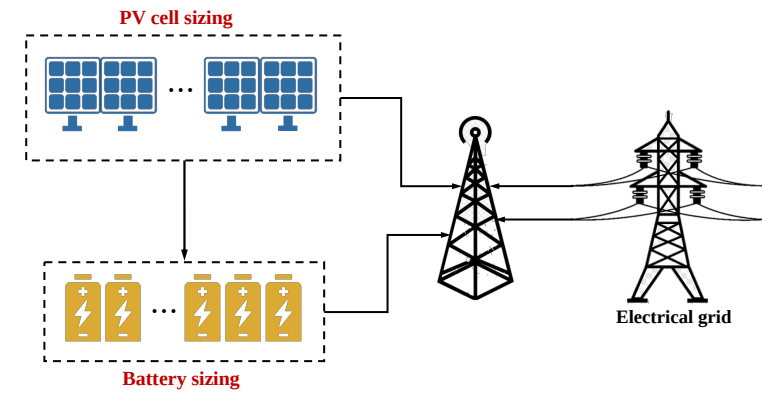

Fig. 13. PV cell and battery sizing of solar-powered BS.

outperforms each one in terms of the grid energy saving.

A combination of physical power line and smart grid was used to minimize net energy cost, which involves the expense of purchasing extra energy and revenue earned by selling extra RE from/to the smart grid and other BSs [21]. After determining the physical power lines based on energy consumption and RE generation of each BS, the authors optimized the amount of power drawn from smart grid and other connected BSs for each BS. Unlike works in which each BS was assumed to have its own RE generator, [91] proposed an energy sharing strategy for a network with shared access to a so-called RE farm where RE is harvested and stored. The strategy determines the optimal power drawn from the RE farm to minimize the energy bill for the user considering space-time varying electricity prices and loads.

\section{E. Dimensioning}

1) PV Cell and Battery Sizing: For the BS powered by solar energy with a battery, as shown in Fig. 13, it is imperative to obtain the optimal size of the PV panel and battery to consider the trade-off between the capital cost and the outage of the system. V. Chamola et al. minimized the overall cost of the system by obtaining the optimal size of the PV panel and battery while satisfying the outage probability constraints and evaluated the proposed framework through empirical solar data [66], [120]. The first work modeled the outage probability of a BS for a given PV panel size and battery by using historical solar irradiance data [120]. Then, the authors proposed a Markov model for characterizing hourly solar energy and used it for optimal PV panel and battery size [121]. Further, the Markov model was also used not only for the harvested solar energy but also for the network traffic and the battery level [66]. With it, the work presented a dimensioning framework which integrates the solar energy, network traffic, and battery level. 


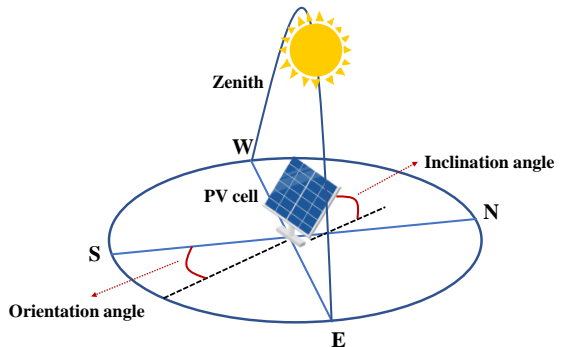

Fig. 14. PV cell angle adjustment illustration including orientation angle and inclination angle [133].

As opposed to the works of V. Chamola et al., the authors [45] considered the average waiting time as a user QoS constraint and minimized the CAPEX of deploying RE-based BSs with optimal solar panel size and battery capacity. In the case of [75], the authors dimensioned the PV system, wind turbine, and the number of batteries so that the generated energy on the worst month would be sufficient to power the BS. The problem of assigning the solar panel and battery size of each node in a solar-powered mesh network was investigated in [60], [65]. Authors in [60] considered the data routing algorithm when sizing the PV system parameters to prevent the outages in the network, and minimize the network deployment cost. Moreover, the authors [65] proposed an algorithm, which introduces a bandwidth deficit when the battery energy drops below a predetermined threshold and minimizes the cost of using other energy sources.

2) PV Cell Angle Adjustment: Unlike the commonly proposed solution to the mismatch between the energy generation profile and BS energy consumption profile, such as energy storage and traffic management, D. Benda et al. optimized the PV cell angle for a BS to meet its energy consumption profile in London, United Kingdom [124], [133], [134]. The daily energy generation profile of a PV cell depends on its angle which is composed of the orientation angle and inclination angle. As shown in Fig. 14, the orientation angle is defined with respect to the southern direction, while the inclination angle is the angle between the PV cell plane and the horizontal plane [133]. The authors [134] investigated the effects of battery capacities and concluded different optimal orientation angles of PV cells with respect to the size of battery capacity. The result in [124] contradicted the general assumption that south-facing PV cell orientation should be chosen as an optimal solution in the northern hemisphere. In [133], the authors jointly optimized the orientation angles of several PV cells in a BS. They proposed deploying PV cells with the same optimized orientation angle in BSs where the energy consumption profile has one significant maximum point. Otherwise, deploying the two groups of PV cells with different orientation angles was suggested.

\section{FEASIBILITy ANALYSis AND APPLICATIONS}

\section{A. Feasibility Analysis}

Considering that the RE power system depends on the environmental conditions of the $\mathrm{BS}$ site, it is essential to conduct

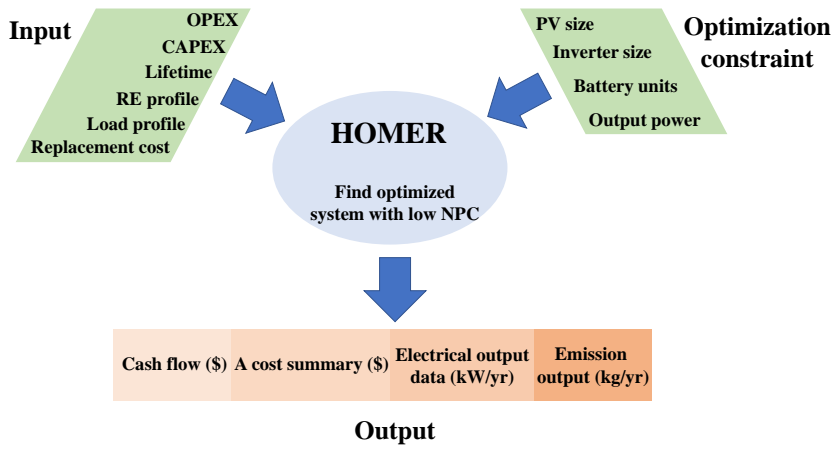

Fig. 15. Architecture of HOMER.

a comprehensive feasibility study in terms of economics and engineering to design a cellular network powered by RE. There have been considerable feasibility studies that properly size and optimize the BS power system using simulation based on the meteorological data and traffic load profile in a specific region. Table VIII shows the works with case studies on feasibility analysis. It also includes the RE source, energy storage system, BS type of each work and region from which the energy source data and the traffic load profile were obtained. Most of the works used HOMER software to evaluate economic and technical feasibility and investigated the optimal BS power supply system with sizing and dimensioning. HOMER simulates the operation of a power system for each hour using energy source profiles, e.g., solar irradiance and wind speeds, equipment cost, energy storage system, and userspecified constraint. As shown in Fig. 15, the simulation results show cash flow, cost summary, electrical output data, and the emission output of harmful gases. The cost summary includes the net present cost (NPC), the cost of electricity $(\mathrm{CoE})$, and the operation cost, and the electrical output data shows electrical load, excess electricity, and electricity production from each energy source. Especially, NPC assesses all the costs that occur within the lifetime of the system, which includes CAPEX, component replacement within the time, and maintenance cost. Based on that, the optimal sizing of the solar PV array and wind turbine has been investigated so that the BS would satisfy its electric demand with the lowest NPC. The simulation results reveal that solar PV system is an attractive option for powering BSs since it saves OPEX with low NPC, CoE, and carbon emissions, whereas wind turbine system is not feasible in all areas. The latest case study work investigated the hybrid solar PV/wind turbine/biomass generator-powered BS with energy sharing and load balancing technique in Bangladesh [144]. Its simulation results not only show that the proposed system has low NPC, CoE, and carbon emission, but also show the performance gain due to the energy sharing and load balancing. The energy sharing mechanism can improve the probability of power supply loss and the proper load balancing lowers the outage probability of user.

\section{B. Applications}

In this subsection, we introduce the applications of RE to the components of cellular networks which serve the network 
TABLE VIII

SIMULATION-BASED CASE STUDY

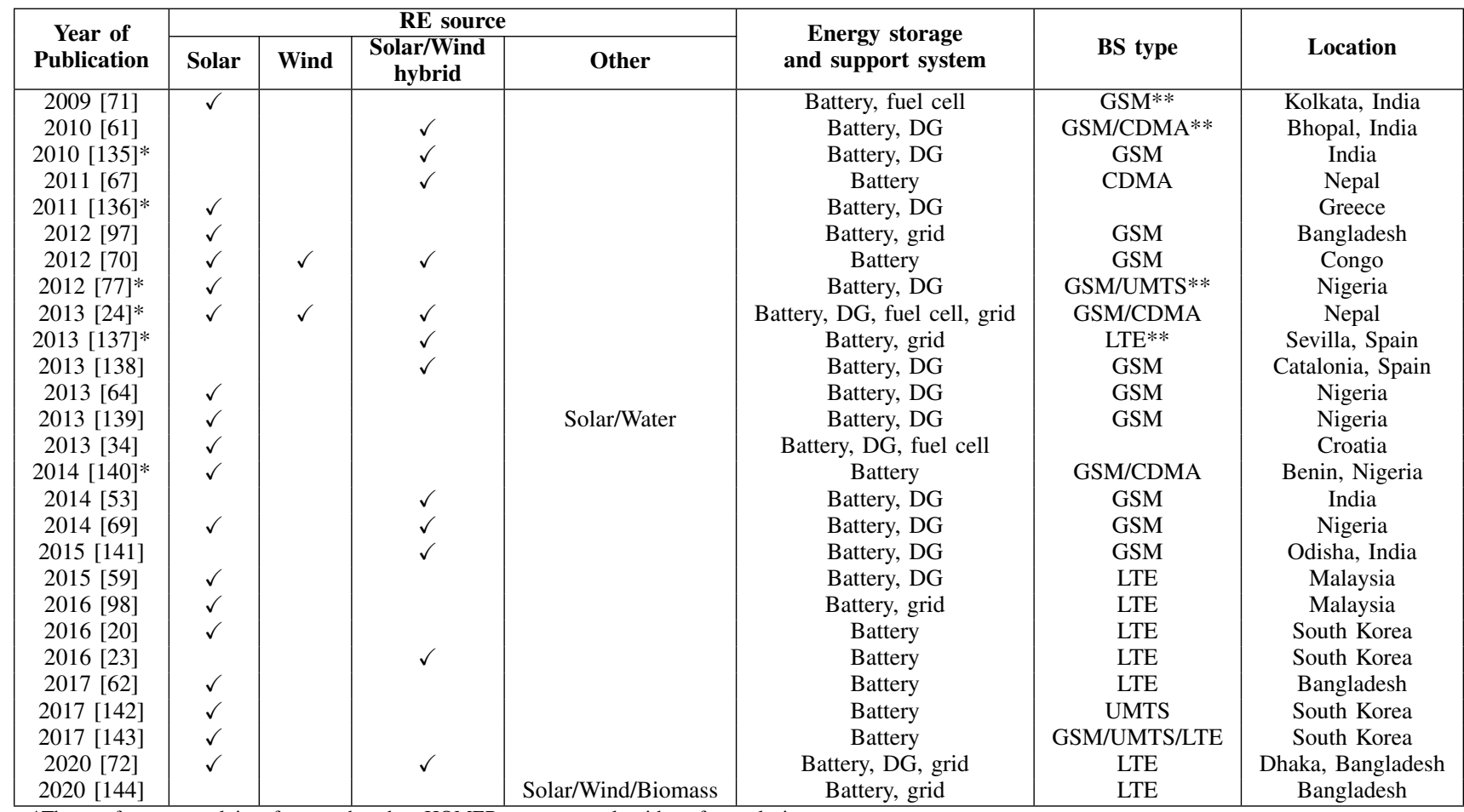

These references exploit software other than HOMER or propose algorithms for analysis.

**Global systems for mobile communications (GSM).

**Code-division multiple access (CDMA).

**Universal mobile telecommunication system (UMTS).

**Long-term evolution (LTE).

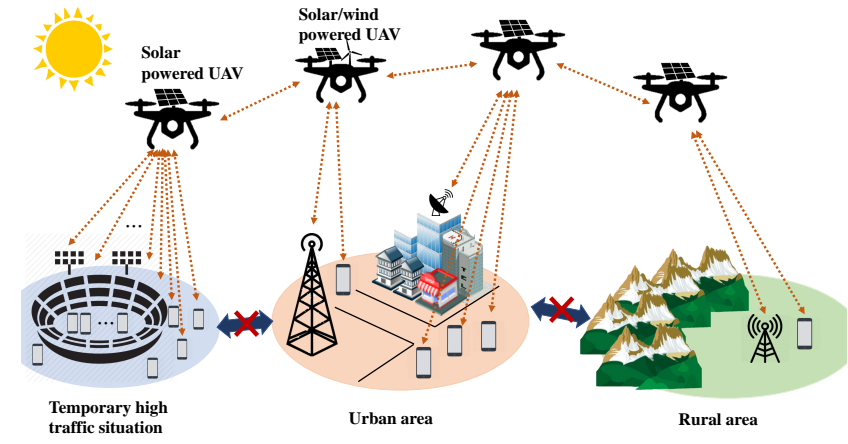

Fig. 16. Use of RE-powered UAVs for high traffic situation and rural area in cellular networks.

in a way that fills the shortage of existing fixed BSs such as aerial base station, NIB, VSAT and, satellite.

1) Aerial Base Station: Future cellular network is envisioned to ubiquitously provide high-data-rate communication services with high reliability. However, the conventional terrestrial BS is not enough to satisfy rural area connectivity, agility, and resilience of the cellular network. Moreover, deploying more fixed BSs is neither cost-effective nor feasible, considering an unexpected disaster where the already deployed infrastructure becomes useless or in temporary high traffic demand situations, e.g., football games, Olympic games, and concerts, which require additional network equipment to provide the traffic storm [145]. In this context, an aerial base station composed of multiple unmanned aerial vehicles (UAVs) equipped with batteries and wireless transceivers, has been proposed as a promising solution since it enables the flexible deployment of communication infrastructure with high maneuverability. Also, its mobility provides an additional spatial degree of freedom due to higher line-of-sight connections with ground users in real time, thus leading to better performance with improved coverage [146]. Fig. 16 describes the various uses of RE-powered UAVs in cellular networks.

Nonetheless, the mechanical movement and wireless communication of UAVs require considerable energy, while the capacity of the on-board energy storage system (i.e., gasoline or on-board batteries) is limited due to its size and weight. This results in a constrained UAV operation time in the air, and UAVs are required to return to a charging station for energy replenishment before the residual energy is depleted, hindering ubiquitous and reliable communications [146], [150]-[153].

To overcome these drawbacks, RE, especially solar power has been considered to prolong the UAV hovering time and eventually realize perpetual flight [154], [155]. The communication with RE-powered UAVs has been addressed as an optimization problem in [49], [147]-[149]. As the most widely adopted design issues regarding the UAV communications are the placement, the trajectory, and the flight time of the UAV, these issues were jointly optimized with on/off switching of the terrestrial BSs [147] or resource allocation [49], [147]- 
TABLE IX

SUMMARY OF RE-POWERED UAV COMMUNICATION WORKS

\begin{tabular}{|c|c|c|c|c|c|c|c|}
\hline \multirow{2}{*}{ References } & \multicolumn{3}{|c|}{ RE source } & \multirow{2}{*}{ Objective } & \multicolumn{2}{|c|}{ Design issues } & \multirow{2}{*}{ QoS } \\
\cline { 2 - 7 } & Solar & Wind & $\begin{array}{c}\text { Solar/Wind } \\
\text { hybrid }\end{array}$ & & UAV movement & Other design issues & \\
\hline$[147]$ & $\checkmark$ & & & $\begin{array}{c}\text { Minimizing the total energy } \\
\text { consumption of HetNets }\end{array}$ & UAV placement & $\begin{array}{c}\text { Switch on/off } \\
\text { of terrestrial BS }\end{array}$ & Received power of user \\
\hline$[148]$ & $\checkmark$ & & & $\begin{array}{c}\text { Maximizing the sum of } \\
\text { user throughput }\end{array}$ & UAV trajectory & $\begin{array}{c}\text { Transmit power, } \\
\text { subcarrier allocation }\end{array}$ & Data rate of user \\
\hline$[49]$ & $\checkmark$ & $\checkmark$ & $\checkmark$ & Minimizing the SNR outage & UAV flight time & Transmit power & Data rate of user \\
\hline$[149]$ & $\checkmark$ & & & $\begin{array}{c}\text { Minimizing the energy } \\
\text { consumption rate of UAV }\end{array}$ & $\begin{array}{c}\text { Transmit power, } \\
\text { data routing, } \\
\text { data rate }\end{array}$ & Data rate of user \\
\hline
\end{tabular}

[149] subject to the minimum QoS constraints such as the data rate of the ground user [49], [147], [148] and the received power [147]. The harvested energy from solar or wind was considered in dealing with the battery and energy consumption of the UAVs. The summary of the works is listed in Table IX. Since work in [147] investigated the placement of multiple UAVs to support switching terrestrial BSs, its result showed the impact of UAVs in ensuring connectivity and supporting overloaded cells with minimum energy consumption. For maximizing the sum of user throughput, the UAV's optimal path initially went to high altitudes to generate sufficient solar energy and then returns to low altitudes to reduce the path loss of the communication [148]. In [49], the author minimized the signal-to-noise ratio (SNR) outage with the optimal UAV flight time and transmit power and derived energy outage probability which occurs when the battery power and the harvested power is not enough to support the flight and data transmission. Its result showed impact of the time of the day, the UAV transmit power, and the flight time on the outage probabilities.

2) NIB: To satisfy the flexibility and the adaptability of mobile networks, the NIB has been proposed, which fits all the software and hardware modules in a handful of physical devices. As NIB does not require any existing infrastructure, it enables the mobile network to be portable and provide connectivity in a wide range of scenarios, including afterdisaster rescue and the recovery, the tactical network, and the temporary events [156]. A NIB is often designed to work completely alone or together with other network components, including other NIBs. In the case of a self-powered NIB, which does not require any power wire to operate, the maximum lifetime is one of the key factors that determine its quality. Since longer service time requires heavy batteries or a power generator, the trade-off between portability and lifetime should be considered when choosing a NIB solution according to its usage scenario.

To extend the service lifetime, solar-powered NIBs "EmergenNet" [157] and "Rescue base station" [158] have been considered. Both studies proposed a quickly deployable, portable, and solar-powered small-scale cellular network, which provides voice calling and text messaging based on the global systems for mobile communications (GSM) within a disaster area. The commercial solar-powered NIB solutions can also be found in [159], [160].

3) Global Connectivity: Investments in cellular networks concentrated in densely populated urban areas, while the

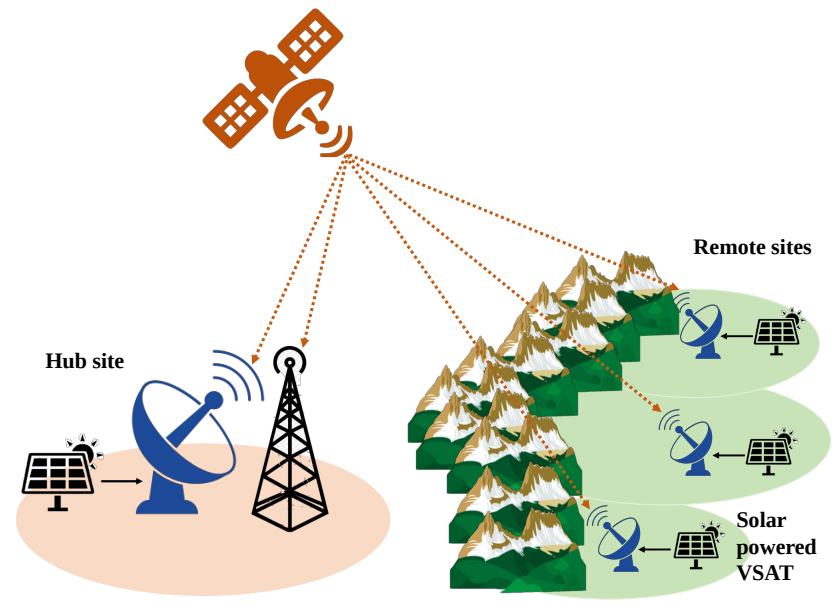

Fig. 17. Satellite communication with solar-powered VSAT in remote sites.

technology is not profitable in rural areas with low population densities lacking reliable power infrastructure. In the case of rural areas, the conventional diesel-based BSs in bad-grid or off-grid sites have been replaced with those powered by RE. Table $\mathrm{X}$ shows the summary of case studies on RE usage as a BS power source in several countries that lack reliable power infrastructure.

To stretch out the mobile network to rural areas, the use of satellite technology has been attractive as a solution.

a) VSAT: VSAT provides a solution for rural area communication to the network operator. As shown in Fig. 17, a VSAT connects the satellite as a small ground station with an antenna diameter of $2.4 \mathrm{~m}$ and it is easy to deploy providing a wide range of communication services with a large hub station or other VSATs [161]. Given the fact that rural areas are often bad-grid or off-grid sites, solar-powered VSAT has been proposed [162]. Also, the International Telecommunication Union, the Universal Postal Union, and the government of India established VSAT-based satellite connectivity powered by solar energy in remote locations of Bhutan [163]. Several companies have come up with solar-powered VSAT solutions. GlobalTT, an European company that provides satellite Internet services mainly in Africa, powers its VSAT with solar panels for easy installation in isolated places [164]. Also, SOLARCOM, a French company of energy supply and communication solutions [165], and MEAPAC, a provider of satellite-based network solutions [166], offer solar-powered 
TABLE $X$

RURAL AREA CASE STUDY [1]

\begin{tabular}{|c|c|c|c|c|c|}
\hline Country & Total number of BSs & Network operator & $\begin{array}{c}\text { Number of } \\
\text { RE-powered BSs }\end{array}$ & $\begin{array}{c}\text { Percentage of } \\
\text { RE-powered BSs }\end{array}$ & $\begin{array}{c}\text { RE source } \\
\text { and support system }\end{array}$ \\
\hline \multirow{3}{*}{ Bangladesh } & \multirow{3}{*}{40,000} & Grameenphone & 1,200 & $3 \%$ & Solar PV \\
\hline & & Robi & 700 & $1.75 \%$ & Solar PV \\
\hline & & Axiata & 400 (Planning) & $1 \%$ & Solar PV \\
\hline $\begin{array}{c}\text { Democratic } \\
\text { Republic of Congo }\end{array}$ & 4,500 & Africa Mobile Networks & 235 & $5.22 \%$ & \\
\hline Fiji & 950 & Digicel Fiji & 30 & $3.15 \%$ & Solar PV + battery + DG \\
\hline Mali & 3,000 & Orange Mali & 680 & $22.67 \%$ & Solar PV + battery \\
\hline Myanmar & 16,500 & (Total) & 1300 & $7.88 \%$ & $\begin{array}{c}\text { Solar PV + battery } \\
\text { Solar PV + battery + DG }\end{array}$ \\
\hline Peru & 11,500 & Internet Para Todos & 3,600 (Planning) & $31.30 \%$ & Solar PV \\
\hline Uganda & 3,800 & American Tower Corporation & 300 & $7.89 \%$ & Solar PV \\
\hline
\end{tabular}

VSATs.

b) Satellite Connectivity Project: Several satellite projects are currently in progress or service to deliver the affordable Internet access globally, and the satellites rely on solar panels for harvesting energy. SpaceX has launched 1,443 satellites for its project called "Starlink constellation" and plans to launch more satellites and install more ground stations to improve data speed, latency, and global coverage [167]. Also, OneWeb plans to provide coverage everywhere above $50^{\circ} \mathrm{N}$ by the end of 2021 , and expects to realize the full global coverage by the the end of 2022 [168]. Amazon and Telesat joined the race as well to provide global Internet services via satellites under the project "Kuiper" [169] and "Telesat Lightspeed" [170], respectively.

\section{FUTURE WORKS}

Even though considerable research works regarding REenabled cellular networks have been conducted, challenges remain to be tackled carefully. As the cellular network technology has rapidly developed and the rapid development is expected to continue along with the surge in data traffic demand, the research on incorporating RE into the network must evolve accordingly. In some countries, MNOs already started launching the newest generation of cellular networks, $5 \mathrm{G}$, whereas it is on track to be implemented in many others. However, the most recent cellular network generation applied in the feasibility studies is 4G, LTE, as shown in Table VIII, and the research for the $5 \mathrm{G}$ case is yet to be done.

While the development of cellular networks was mostly driven by the demand for high data rates and capacity, recent evolution concentrated on the emergence of the Internet of Everything (IoE) system. It connects millions of people and billions of machines requiring ultra-reliable, low latency communication (URLLC) and self-sustaining networks (SSNs) with service of extended reality, autonomous systems, and brain-computer interfaces. Especially, SSNs should be able to not only adapt their functions to specific environmental states but also sustain their resources through energy harvesting [171]. Nevertheless, the marketed 5G system is yet to fully support the IoE system with URLLC and SSNs passing them on to $6 \mathrm{G}$, and the driving trends of $6 \mathrm{G}$ propose new performance metrics, functions, and technologies that needs to be considered. Hence, RE should be more heavilty utilized in cellular networks to realize SSNs in the future. Also, RE incorporation should not focus only on high data rate and capacity like the development of the past generations, and the emergence of IoE systems with the new performance metrics, functions, and techniques must be considered. The following paragraphs explain suggested future research directions on REenabled cellular networks from the perspective of the new characteristics of the IoE system.

1) Performance metrics: Many of the above-mentioned studies in this article formulated optimization problems aimed at minimizing the energy consumption, maximizing the profits of MNO, maximizing the energy efficiency, and minimizing the energy cost with the constraints for the minimum QoS of users. Unlike the classical QoS such as latency and data rate, a new concept, namely the quality of physical experience (QoPE) is needed to satisfy not only the technical requirements, but also perceptual requirements in IoE services, especially the extended reality. QoPE merges physical factors from the users with the conventional QoS and the quality of experience (QoE) [171]. Secrecy can be another performance metric for $6 \mathrm{G}$ cellular network and is related to blockchain and distributed ledger technology, which will be potentially used in the $6 \mathrm{G}$ cellular network. The blockchain is expected to revolutionize the network paradigm by eliminating central authority and the distributed authorized party chaining blocks together realizes transactions. These technologies improve network security and reduce costs. Therefore, advanced performance metrics along with communication technologies should be considered in the future RE-enabled networks research.

2) Functions: Unlike the past five generations, which had one exclusive function of communication, $6 \mathrm{G}$ is envisioned to deliver multiple services including communications, sensing, control, localization, and computing [172]. Therefore, RE must be integrated into the cellular network in a way that considers not only communication but also other functions the future cellular network can bring to the users. Specifically, previous studies assumed the BS power consumption model, which takes into account only the communication function of the network, as introduced in Section II.C. Instead, the existing research should be revisited based on new energy consumption models of other multiple services in the future $6 \mathrm{G}$ network.

3) Techniques: Data size will continue to increase in the form of massive and distributed data and machine learning 
with big data training will be the most innovative technique for designing a 6G autonomous system [173]. Machine learning was already exploited for RE-based HetNets [73], [174], [175]. The authors [73] maximized energy efficiency through traffic offloading, and power allocation, whereas the work in [174] obtained the optimal BS sleep mode control and the energy sharing mechanism for the minimum grid energy consumption. In the case of [175], the work addressed user scheduling and resource allocation to maximize energy efficiency. However, the works are limited to HetNets, and the existing works on green communication can be revisited using machine learning techniques.

In the $6 \mathrm{G}$ cellular network, there exist several new changes and technologies that can be combined with RE and require a re-examination of existing studies on RE-enabled networks, including; i) cell-free access scheme, ii) optical wireless communication, iii) terahertz (THz) communication, iv) braincomputer interface, v) caching and edge computing.

- Cell-free massive MIMO: Cell-free massive MIMO aims for nearly uniform achievable rates and seamless handover across the network's coverage area. This is realized by combining massive MIMO, small cells, and CoMP with many cooperating access points (AP) distributed over the coverage [176]. The large number of APs jointly serve users in the network and leads to energy consumption challenge, which motivates the incorporation of RE.

- THz communication: As the per-user bit rate in 6G network is expected to be approximately $1 \mathrm{~TB} / \mathrm{s}$, higher frequencies, such as mmWave and $\mathrm{THz}$ band will play a key role in the $6 \mathrm{G}$ network [177]. Accordingly, there will be challenges in hardware and software implementation operating at these high frequencies, and a new energy consumption model will be required to match the high frequencies.

- Brain-computer interface: The brain-computer interface is another IoE service in 6G. Using the tiny devices, which can be worn, implanted, and embedded, people can interact with the environment around them. For example, people can communicate and control their environment through gestures [171]. Considering that the worn, implanted, and embedded devices with a battery will cause inconvenience, new energyharvesting modules for such devices need to be developed, obviating the need for a battery. Also, dimensioning the energy harvesting module should be essential for the trade off between cost and performance.

- Optical wireless communication (OWC) : Along with the $\mathrm{THz}$ band, the optical frequency band is another key enabler for $6 \mathrm{G}$, which requires a high data density of $100 \mathrm{~GB} / \mathrm{s} / \mathrm{m}^{2}$ and low latency of $10 \mu \mathrm{s}$ [172], [178]. In OWC, the photodetector converts the propagated optical signal into an electrical signal. The works in [178]-[181] proposed an OWC receiver using a solar panel as a photodetector so that it can convert the optical signal into an electrical signal without any external power and even generate extra energy. Thus, OWC offers great potential for realizing $6 \mathrm{G}$, especially when it is powered by solar energy, considering the high data rate and SSNs of $6 \mathrm{G}$.

- Caching and edge computing: While caching at the network edge has been envisioned as a key technique for reducing congestion and improving QoS, it poses a challenge on energy consumption. Hence, the works in [48], [182]-[185] proposed RE-aware caching together with BS sleep mode control [48], [182], routing [184], or user association [185]. In $6 \mathrm{G}$, all user-specific computation and intelligence may move to the edge cloud so that the edge can provide lowlatency user applications such as mobile virtual reality and mixed reality applications. Edge computing can also be used in a thin user client, which is a low-energy device capable of interacting with human senses or neural systems [186]. Therefore, energy consumption challenges in the edge will persist, and RE-aware edge computing can offer a promising solution.

\section{CONCLUSION}

This survey paper discusses RE-enabled cellular networks which reduce energy consumption along with $\mathrm{CO}_{2}$ emission and offer an alternative power source in off-grid cases. We discussed the components of RE-powered BSs, and introduced the energy sources, energy storage system, BS, and controller by investigating the RE sources, DG, battery, fuel cell, BS power consumption model, traffic model, and energyharvesting model. Then, we classified and discussed optimization and design issues in RE-enabled cellular networks. Moreover, we presented feasibility studies that properly optimize the RE-powered BS system for specific regions. Lastly, we introduced other applications in which RE was adopted as an energy source for components other than terrestrial BSs in a cellular network. This survey attempts to briefly explore the current research with respect to the RE-enabled cellular networks and the comprehensive overview provided in this work can serve as a guideline for further research on REenabled cellular network.

\section{REFERENCES}

[1] D. Tillekeratne, "Renewable energy for mobile towers: Opportunities for low- and middle-income countries," Global System Mobile Association (GSMA), Tech. Rep., Sep. 2020. [Online]. Available: https://www.gsma.com/mobilefordevelopment/resources/renewableenergy-for-mobile-towers-opportunities-for-low-and-middle-incomecountries/

[2] "Cisco Annual Internet Report (2018-2023) White Paper," Cisco, Tech. Rep., Mar. 2020. [Online]. Available: https://www.cisco.com/c/en/us/solutions/collateral/executiveperspectives/annual-internet-report/white-paper-c11-741490.html

[3] "Between 10 and $20 \%$ of electricity consumption from the ICT sector in 2030?" Enerdata, Tech. Rep., Aug. 2018. [Online]. Available: https://www.enerdata.net/publications/executive-briefing/between-10and-20-electricity-consumption-ict-sector-2030.html

[4] G. Auer, V. Giannini, C. Desset, I. Godor, P. Skillermark, M. Olsson, M. A. Imran, D. Sabella, M. J. Gonzalez, O. Blume, and A. Fehske, "How much energy is needed to run a wireless network?" IEEE Wireless Commun., vol. 18, no. 5, pp. 40-49, Oct. 2011.

[5] "The Mobile Economy 2020," Global System Mobile Association (GSMA), Tech. Rep., Sep. 2020. [Online]. Available: https://www.gsma.com/mobileeconomy/

[6] "Global warming of $1.5^{\circ} \mathrm{C}$," Intergovernmental Panel on Climate Change (IPCC), Tech. Rep., 2019. [Online]. Available: https://www.ipcc.ch/sr15/

[7] United Nations (UN), "Sustainable Development / 17 Goals," https://sdgs.un.org/goals. 
[8] K. Son, H. Kim, Y. Yi, and B. Krishnamachari, "Base station operation and user association mechanisms for energy-delay tradeoffs in green cellular networks," IEEE J. Sel. Areas Commun., vol. 29, no. 8, pp. 1525-1536, Sep. 2011.

[9] A. P. Bianzino, C. Chaudet, D. Rossi, and J. Rougier, "A survey of green networking research," IEEE Commun. Surv. Tutor., vol. 14, no. 1, pp. 3-20, 2012.

[10] Z. Hasan, H. Boostanimehr, and V. K. Bhargava, "Green cellular networks: A survey, some research issues and challenges," IEEE Commun. Surv. Tutor, vol. 13, no. 4, pp. 524-540, 2011.

[11] J. Wu, Y. Zhang, M. Zukerman, and E. K. Yung, "Energy-efficient basestations sleep-mode techniques in green cellular networks: A survey," IEEE Commun. Surv. Tutor, vol. 17, no. 2, pp. 803-826, 2015.

[12] M. Ku, W. Li, Y. Chen, and K. J. Ray Liu, "Advances in energy harvesting communications: Past, present, and future challenges," IEEE Commun. Surv. Tutor, vol. 18, no. 2, pp. 1384-1412, 2016.

[13] M. Alsharif, J. Kim, and J. Kim, "Green and sustainable cellular base stations: An overview and future research directions," Energies, vol. 10, p. 587, Apr. 2017.

[14] A. Mohamad Aris and B. Shabani, "Sustainable power supply solutions for off-grid base stations," Energies, vol. 8, p. 10904, Sep. 2015.

[15] J. Lorincz and I. Bule, "Renewable energy sources for power supply of base station sites," International J. Business Data Commun. Netw. $(I J B D C N)$, vol. 9, pp. 53-74, Jan. 2012.

[16] V. Chamola and B. Sikdar, "Solar powered cellular base stations: Current scenario, issues and proposed solutions," IEEE Commun. Mag., vol. 54, no. 5, pp. 108-114, May 2016.

[17] T. Han and N. Ansari, "Powering mobile networks with green energy," IEEE Wireless Commun., vol. 21, no. 1, pp. 90-96, Feb. 2014.

[18] T. Han and N. Ansari, "On greening cellular networks via multicell cooperation," IEEE Wireless Commun., vol. 20, no. 1, pp. 82-89, Feb. 2013.

[19] J. Xu, L. Duan, and R. Zhang, "Cost-aware green cellular networks with energy and communication cooperation," IEEE Commun. Mag., vol. 53, no. 5, pp. 257-263, May 2015

[20] M. Alsharif and J. Kim, "Optimal solar power system for remote telecommunication base stations: A case study based on the characteristics of South Korea's solar radiation exposure," Sustainability, vol. 8, p. 942, Sep. 2016.

[21] M. J. Farooq, H. Ghazzai, A. Kadri, H. ElSawy, and M. Alouini, "A hybrid energy sharing framework for green cellular networks," IEEE Trans. Commun., vol. 65, no. 2, pp. 918-934, Feb. 2017.

[22] F. O. Hocaoğlu, "Novel analytical hourly solar radiation models for photovoltaic based system sizing algorithms," Energy Convers. Manag., vol. 51, no. 12, pp. 2921-2929, Dec. 2010.

[23] M. Alsharif and J. Kim, "Hybrid off-grid SPV/WTG power system for remote cellular base stations towards green and sustainable cellular networks in South Korea," Energies, vol. 10, p. 9, Dec. 2016.

[24] S. Paudel, M. Dahal, M. Adhikari, and J. Shrestha, "Technical and economic assessment of renewable energy sources for telecom application: A case study of Nepal telecom," in Proc. of the 5th International Conf. on Power and Energy Sys. (ICPS), Kathmandu, Nepal, Oct. 2013, pp. $1-11$.

[25] C. Wang and M. H. Nehrir, "Power management of a stand-alone wind/photovoltaic/fuel cell energy system," IEEE Trans. Energy Convers., vol. 23 , no. 3, pp. 957-967, Sep. 2008.

[26] A. Jahid, M. S. Islam, M. S. Hossain, M. E. Hossain, M. K. H. Monju, and M. F. Hossain, "Toward energy efficiency aware renewable energy management in green cellular networks with joint coordination," IEEE Access, vol. 7, pp. 75 782-75 797, 2019.

[27] R. Dufo-López and J. L. Bernal-Agustín, "Grid-connected renewable electricity storage: Batteries vs. hydrogen," in Advances in Mechanical and Electronic Engineering, D. Jin and S. Lin, Eds. Berlin, Heidelberg: Springer Berlin Heidelberg, 2013, pp. 221-225.

[28] J. M. L. R. Dufo-López and J. L. Bernal-Agustín, "Comparison of different lead-acid battery lifetime prediction models for use in simulation of stand-alone photovoltaic systems," Appl. Energy, vol. 115 , pp. 242-253, 2014

[29] A. H. Shahirinia, S. M. M. Tafreshi, A. H. Gastaj, and A. R. Moghaddomjoo, "Optimal sizing of hybrid power system using genetic algorithm," in Proc. International Conf. Future Power Sys., Amsterdam, Netherlands, Nov. 2005, pp. 1-6.

[30] R. Dufo-López, J. L. Bernal-Agustín, and J. A. Domínguez-Navarro, "Generation management using batteries in wind farms: Economical and technical analysis for Spain," Energy Policy, vol. 37, no. 1, pp. 126-139, Sep. 2009.
[31] P. A. Lehman, C. E. Chamberlin, J. I. Zoellick, and R. A. Engel, "A photovoltaic/fuel cell power system for a remote telecommunications station," in Proc. 28th IEEE Photovoltaic Specialists Conf. (Cat. No.00CH37036), Anchorage, AK, USA, Sep. 2000, pp. 1552-1555.

[32] P. Lehman, C. Chamberlin, J. Zoellick, R. Engel, and D. Rommel, "Fuel cell/photovoltaic integrated power system for a remote telecommunications repeater," in Proc. 14th World Hydrogen Energy Conf., Montreal, QC, Canada, Jun. 2002.

[33] S. R. Vosen and J. O. Keller, "Hybrid energy storage systems for standalone electric power systems: optimization of system performance and cost through control strategies," Int. J. Hydrog. Energy, vol. 24, no. 12 , pp. 1139-1156, Nov. 1999.

[34] D. Bezmalinović, F. Barbir, and I. Tolj, "Techno-economic analysis of PEM fuel cells role in photovoltaic-based systems for the remote base stations," Int. J. Hydrog. Energy, vol. 38, no. 1, pp. 417-425, Jan. 2013.

[35] M. Y. Suberu, M. W. Mustafa, and N. Bashir, "Energy storage systems for renewable energy power sector integration and mitigation of intermittency," Renew. Sust. Energ. Rev., vol. 35, pp. 499-514, 2014. [Online]. Available: https://www.sciencedirect.com/science/article/pii/S1364032114002366

[36] X. Wang, Y. Zhang, G. B. Giannakis, and S. Hu, "Robust smartgrid-powered cooperative multipoint systems," IEEE Trans. Wirel. Commun., vol. 14, no. 11, pp. 6188-6199, Jun. 2015.

[37] X. Wang, Y. Zhang, T. Chen, and G. B. Giannakis, "Dynamic energy management for smart-grid-powered coordinated multipoint systems," IEEE J. Sel. Areas Commun., vol. 34, no. 5, pp. 1348-1359, Jan. 2016.

[38] D. Zeng, J. Zhang, L. Gu, S. Guo, and J. Luo, "Energy-efficient coordinated multipoint scheduling in green cloud radio access network," IEEE Trans. Veh. Technol., vol. 67, no. 10, pp. 9922-9930, Aug. 2018.

[39] T. Han and N. Ansari, "A traffic load balancing framework for softwaredefined radio access networks powered by hybrid energy sources," IEEE/ACM Trans. Netw., vol. 24, no. 2, pp. 1038-1051, Apr. 2016.

[40] H. Xu, T. Zhang, Z. Zeng, and D. Liu, "Joint base station operation and user association in cloud based HCNs with hybrid energy sources," in Proc. IEEE 26th Annual International Symp. on Personal, Indoor, and Mobile Radio Commun. (PIMRC), Hong Kong, China, Aug. 2015, pp. 2369-2373.

[41] V. Chamola, B. Sikdar, and B. Krishnamachari, "Delay aware resource management for grid energy savings in green cellular base stations with hybrid power supplies," IEEE Trans. Commun., vol. 65, no. 3, pp. 1092-1104, Mar. 2017.

[42] L. Tang and H. Hu, "Multi-objective optimization of user association in HetNets with hybrid power supply," IEEE Trans. Green Commun. Netw, vol. 3, no. 4, pp. 933-941, Dec. 2019.

[43] Q. Fan and N. Ansari, "Towards throughput aware and energy aware traffic load balancing in heterogeneous networks with hybrid power supplies," IEEE Trans. Green Commun. Netw., vol. 2, no. 4, pp. 890898, Dec. 2018.

[44] D. Liu, Y. Chen, K. K. Chai, and T. Zhang, "Distributed delay-energy aware user association in 3-tier HetNets with hybrid energy sources," in Proc. IEEE Global Commun. Conf. Workshops (GC Wkshps), Austin, TX, USA, Dec. 2014, pp. 1109-1114.

[45] T. Han and N. Ansari, "Provisioning green energy for base stations in heterogeneous networks," IEEE Trans. Veh. Technol., vol. 65, no. 7, pp. 5439-5448, Jul. 2016.

[46] W. Sun and J. Liu, "Coordinated multipoint-based uplink transmission in Internet of Things powered by energy harvesting," IEEE Internet Things J., vol. 5, no. 4, pp. 2585-2595, Aug. 2018.

[47] D. W. K. Ng, E. S. Lo, and R. Schober, "Energy-efficient resource allocation in OFDMA systems with hybrid energy harvesting base station," IEEE Trans. Wirel. Commun., vol. 12, no. 7, pp. 3412-3427, Jul. 2013.

[48] D. Xu, H. Jin, C. Zhao, and D. Liang, "Joint caching and sleepactive scheduling for energy-harvesting based small cells," in Proc. 9th International Conf. Wireless Commun. and Signal Process. (WCSP), Chennai, India, Mar. 2017, pp. 1-6.

[49] S. Sekander, H. Tabassum, and E. Hossain, "Statistical performance modeling of solar and wind-powered UAV communications," IEEE Trans. Mob. Comput., pp. 1-15, Apr. 2020.

[50] H. S. Dhillon, Y. Li, P. Nuggehalli, Z. Pi, and J. G. Andrews, "Fundamentals of heterogeneous cellular networks with energy harvesting," IEEE Trans. Wirel. Commun., vol. 13, no. 5, pp. 2782-2797, May 2014.

[51] Y. Zhang, N. Gatsis, and G. B. Giannakis, "Robust energy management for microgrids with high-penetration renewables," IEEE Trans. Sustain. Energy, vol. 4, no. 4, pp. 944-953, Oct. 2013. 
[52] Y. C. Chen and A. D. Dominguez-Garcia, "A method to study the effect of renewable resource variability on power system dynamics," IEEE Trans. Power Syst., vol. 27, no. 4, pp. 1978-1989, Nov. 2012.

[53] S. Goel and S. M. Ali, "Cost analysis of solar/wind/diesel hybrid energy systems for telecom tower by using HOMER," Int. J. Renew. Energy. Res., vol. 4, no. 2, pp. 305-311, Apr. 2014.

[54] D. Liu, Y. Chen, K. K. Chai, T. Zhang, and C. Pan, "Adaptive user association in HetNets with renewable energy powered base stations," in Proc. 21st International Conf. Telecommun. (ICT), Lisbon, Portugal, May 2014, pp. 93-97.

[55] B. Xu, Y. Chen, M. Elkashlan, T. Zhang, and K. Wong, "User association in massive MIMO and mmWave enabled HetNets powered by renewable energy," in Proc. IEEE Wireless Commun. Netw. Conf., Doha, Qatar, Apr. 2016, pp. 1-6.

[56] S. Hashimoto, T. Yachi, and T. Tani, "A new stand-alone hybrid power system with wind generator and photovoltaic modules for a radio base station," in Proc. 26th Annual International Telecommun. Energy Conf., Chicago, IL, USA, Sep. 2004, pp. 254-259.

[57] V. Chamola, B. Krishnamachari, and B. Sikdar, "An energy and delay aware downlink power control strategy for solar powered base stations," IEEE Commun. Lett., vol. 20, no. 5, pp. 954-957, May 2016.

[58] — , "Green energy and delay aware downlink power control and user association for off-grid solar-powered base stations," IEEE Syst. J., vol. 12, no. 3, pp. 2622-2633, Sep. 2018.

[59] M. H. Alsharif, R. Nordin, and M. Ismail, "Energy optimisation of hybrid off-grid system for remote telecommunication base station deployment in Malaysia," EURASIP J. Wireless Commun. Netw., vol. 2015, no. 64, Mar. 2015.

[60] G. H. Badawy, A. A. Sayegh, and T. D. Todd, "Energy provisioning in solar-powered wireless mesh networks," IEEE Trans. Veh. Technol., vol. 59, no. 8, pp. 3859-3871, Oct. 2010 .

[61] P. Nema, R. Nema, and S. Rangnekar, "PV-solar/wind hybrid energy system for GSM/CDMA type mobile telephony base station," Int. J. Energy Environ., vol. 1(2), pp. 359-366, Jan. 2010

[62] A. Jahid and M. S. Hossain, "Feasibility analysis of solar powered base stations for sustainable heterogeneous networks," in Proc. IEEE Region 10 Humanitarian Technol. Conf. (R10-HTC), Bangladesh, Dhaka, 2017, pp. 686-690.

[63] E. Ofry and A. Braunstein, "The loss of power supply probability as a technique for designing stand-alone solar electrical (photovoltaic) systems," IEEE Trans. Power Syst., vol. PAS-102, no. 5, pp. 11711175, May 1983.

[64] V. Ani and E. Nnene, "Simulation and optimization of hybrid diesel power generation system for GSM base station site in Nigeria," Electron. J. Energy Environ., vol. 1, pp. 37-56, May 2013.

[65] A. Farbod and T. D. Todd, "Resource allocation and outage control for solar-powered WLAN mesh networks," IEEE Trans. Mob Comput. vol. 6, no. 8, pp. 960-970, Aug. 2007.

[66] V. Chamola and B. Sikdar, "Power outage estimation and resource dimensioning for solar powered cellular base stations," IEEE Trans. Commun., vol. 64, no. 12, pp. 5278-5289, Dec. 2016.

[67] S. Paudel, J. N. Shrestha, F. J. Neto, J. A. F. Ferreira, and M. Adhikari, "Optimization of hybrid $\mathrm{PV} /$ wind power system for remote telecom station," in Proc. Int. Conf. Power Energy Syst., Chennai, India, Dec. 2011, pp. 1-6.

[68] S. Ashok, "Optimised model for community-based hybrid energy system," Renew. Energ., vol. 32, no. 7, pp. 1155-1164, Jun. 2007.

[69] L. J. Olatomiwa, S. Mekhilef, and A. S. N. Huda, "Optimal sizing of hybrid energy system for a remote telecom tower: A case study in Nigeria," in Proc. IEEE Conf. Energy Convers. (CENCON), Johor Bahru, Malaysia, Oct. 2014, pp. 243-247.

[70] K. Kusakana and H. Vermaak, "Hybrid renewable power systems for mobile telephony base stations in developing countries," Renew. Energ. vol. 51(C), pp. 419-425, Mar. 2013.

[71] P. Bajpai, N. P. Prakshan, and N. K. Kishore, "Renewable hybrid standalone telecom power system modeling and analysis," in Proc. IEEE Region 10 Conf., Singapore, Nov. 2009, pp. 1-6.

[72] A. Jahid, M. S. Hossain, M. K. H. Monju, M. F. Rahman, and M. F. Hossain, "Techno-economic and energy efficiency analysis of optimal power supply solutions for green cellular base stations," IEEE Access, vol. 8, pp. 43776-43 795, 2020

[73] B. Gu, Y. Wei, X. Liu, M. Song, and Z. Han, "Traffic offloading and power allocation for green HetNets using reinforcement learning method," in Proc. IEEE Global Commun. Conf. (GLOBECOM), Waikoloa, HI, USA, Dec. 2019, pp. 1-6.
[74] T. Zhang, H. Xu, D. Liu, N. C. Beaulieu, and Y. Zhu, "User association for energy-load tradeoffs in HetNets with renewable energy supply," IEEE Commun. Lett., vol. 19, no. 12, pp. 2214-2217, Dec. 2015.

[75] M. A. Marsan, G. Bucalo, A. Di Caro, M. Meo, and Y. Zhang, "Towards zero grid electricity networking: Powering BSs with renewable energy sources," in Proc. IEEE Int. Conf. Commun. Workshops (ICC), Budapest, Hungary, Jun. 2013, pp. 596-601.

[76] B. Xu, Y. Chen, J. Requena Carrión, J. Loo, and A. Vinel, "Energyaware power control in energy cooperation aided millimeter wave cellular networks with renewable energy resources," IEEE Access, vol. 5, pp. 432-442, Jan. 2016.

[77] F. Nasir, A. Adeseko, M. Y. Muhammed, and A. Abdulkarim, "Hybrid power systems for cell sites in mobile cellular networks," J. Select. Areas Renew. Sustain. Energy, pp. 8-12, Jan. 2012.

[78] J. Xu and R. Zhang, "CoMP meets smart grid: A new communication and energy cooperation paradigm," IEEE Trans. Veh. Technol., vol. 64 , no. 6 , pp. 2476-2488, Jun. 2015.

[79] — "Cooperative energy trading in CoMP systems powered by smart grids," IEEE Trans. Veh. Technol., vol. 65, no. 4, pp. 2142-2153, Apr. 2016.

[80] Y. Chiang and W. Liao, "Green multicell cooperation in heterogeneous networks with hybrid energy sources," IEEE Trans. Wirel. Commun., vol. 15 , no. 12 , pp. $7911-7925$, Dec. 2016.

[81] _ "Renewable energy aware cluster formation for CoMP transmission in green cellular networks," in Proc. IEEE Global Commun. Conf. (GLOBECOM), Austin, TX, USA, Dec. 2014, pp. 4430-4435.

[82] A. Lalitha, S. Mondal, S. K. V, and V. Sharma, "Power-optimal scheduling for a green base station with delay constraints," in Proc. National Conf. Commun. (NCC), New Delhi, India, Feb. 2013, pp. $1-$ 5.

[83] M. J. Neely, A. Saber Tehrani, and A. G. Dimakis, "Efficient algorithms for renewable energy allocation to delay tolerant consumers," in Proc. 1st First IEEE Int. Conf. Smart Grid Commun., Gaithersburg, MD ,USA, Oct. 2010, pp. 549-554.

[84] M. Sheng, D. Zhai, X. Wang, Y. Li, Y. Shi, and J. Li, "Intelligent energy and traffic coordination for green cellular networks with hybrid energy supply," IEEE Trans. Veh. Technol., vol. 66, no. 2, pp. 1631-1646, Feb. 2017.

[85] T. Han and N. Ansari, "Green-energy aware and latency aware user associations in heterogeneous cellular networks," in Proc. IEEE Global Commun. Conf. (GLOBECOM), Atlanta, GA, USA, Dec. 2013, pp. 4946-4951.

[86] Q. Fan and N. Ansari, "Throughput aware and green energy aware user association in heterogeneous networks," in Proc. IEEE Int. Conf. Commun. (ICC), Paris, France, May 2017, pp. 1-6.

[87] D. Liu, Y. Chen, K. K. Chai, and T. Zhang, "Backhaul aware joint uplink and downlink user association for delay-power trade-offs in HetNets with hybrid energy sources," Trans. Emerg. Telecommun. Technol., vol. 28, no. 3, p. e2968, Mar. 2017.

[88] F. Ahmed, N. Muhammad, W. Ejaz, M. Iqbal, and H. S. Kim, "Renewable energy assisted traffic aware cellular base station energy cooperation," Energies, vol. 11, p. 99, Jan. 2018

[89] Y. Chia, S. Sun, and R. Zhang, "Energy cooperation in cellular networks with renewable powered base stations," IEEE Trans. Wirel. Commun., vol. 13, no. 12, pp. 6996-7010, Dec. 2014.

[90] S. Lakshminarayana, T. Q. S. Quek, and H. V. Poor, "Cooperation and storage tradeoffs in power grids with renewable energy resources," IEEE J. Sel. Areas Commun., vol. 32, no. 7, pp. 1386-1397, Jul. 2014.

[91] J. Leithon, T. J. Lim, and S. Sun, "Cost-aware renewable energy management with application in cellular networks," IEEE Trans. Green Commun. Netw., vol. 2, no. 1, pp. 316-326, Mar. 2018.

[92] D. Li, W. Saad, I. Guvenc, A. Mehbodniya, and F. Adachi, "Decentralized energy allocation for wireless networks with renewable energy powered base stations," IEEE Trans. Commun., vol. 63, no. 6, pp. 21262142, Jun. 2015

[93] J. Peng, P. Hong, and K. Xue, "Optimal power management under delay constraint in cellular networks with hybrid energy sources," Comput. Netw., vol. 78, pp. 107-118, Feb. 2015.

[94] N. Ben Rached, H. Ghazzai, A. Kadri, and M. Alouini, "Energy management optimization for cellular networks under renewable energy generation uncertainty," IEEE Trans. Green Commun. Netw., vol. 1, no. 2, pp. 158-166, Jun. 2017.

[95] T. Han and N. Ansari, "On optimizing green energy utilization for cellular networks with hybrid energy supplies," IEEE Trans. Wirel. Commun., vol. 12, no. 8, pp. 3872-3882, Aug. 2013. 
[96] N. A. Chughtai, M. Ali, S. Qaisar, M. Imran, M. Naeem, and F. Qamar, "Energy efficient resource allocation for energy harvesting aided $\mathrm{H}$ CRAN," IEEE Access, vol. 6, pp. 43 990-44 001, 2018.

[97] S. Moury, M. Nazim Khandoker, and S. M. Haider, "Feasibility study of solar PV arrays in grid connected cellular BTS sites," in Proc. Int. Conf. Advances in Power Convers. and Energy Technol. (APCET), Mylavaram, India, Aug. 2012, pp. 1-5.

[98] M. H. Alsharif, R. Nordin, and M. Ismail, "Intelligent cooperation management among solar powered base stations towards a green cellular network in a country with an equatorial climate," Springer Telecommun. Syst., vol. 62, pp. 179-198, 2016.

[99] Z. Chang, C. Jing, X. Guo, Z. Han, and T. Ristaniemi, "Resource allocation for wireless virtualized HetNet with caching and hybrid energy supply," in Proc. IEEE Wireless Commun. Netw. Conf. (WCNC), Barcelona, Spain, Apr. 2018, pp. 1-6.

[100] D. Liu, Y. Chen, K. K. Chai, T. Zhang, and M. Elkashlan, "Twodimensional optimization on user association and green energy allocation for HetNets with hybrid energy sources," IEEE Trans. Commun., vol. 63, no. 11, pp. 4111-4124, Nov. 2015.

[101] Q. Han, B. Yang, G. Miao, C. Chen, X. Wang, and X. Guan, "Backhaulaware user association and resource allocation for energy-constrained HetNets," IEEE Trans. Veh. Technol., vol. 66, no. 1, pp. 580-593, Jan. 2017

[102] L. A. Fletscher, L. A. Suárez, D. Grace, C. V. Peroni, and J. M Maestre, "Energy-aware resource management in heterogeneous cellular networks with hybrid energy sources," IEEE Trans. Netw. Service Manag, vol. 16, no. 1, pp. 279-293, Mar. 2019.

[103] D. Liu, Y. Chen, K. K. Chai, T. Zhang, and K. Han, "Joint user association and green energy allocation in HetNets with hybrid energy sources," in Proc. IEEE Wireless Commun. Netw. Conf. (WCNC), New Orleans, LA, USA, Mar. 2015, pp. 1542-1547.

[104] T. Han and N. Ansari, "ICE: Intelligent cell breathing to optimize the utilization of green energy," IEEE Commun. Lett., vol. 16, no. 6, pp. 866-869, Jun. 2012.

[105] L. Chen, F. R. Yu, H. Ji, B. Rong, X. Li, and V. C. M. Leung, "Energy harvesting small cell networks with full-duplex self-backhaul and massive MIMO," in Proc. IEEE Int. Conf. Commun. (ICC), Kuala Lumpur, Malaysia, May 2016, pp. 1-6.

[106] G. Zhang, Y. Cao, L. Wang, and D. Li, "Operation cost minimization for base stations with heterogenous energy supplies and sleep-awake mode: A two-timescale approach," IEEE Trans. Cognitive Commun. Netw., vol. 4, no. 4, pp. 908-918, Dec. 2018.

[107] H. Lee and J. Lee, "Adaptive traffic management and energy cooperation in renewable-energy-powered cellular networks," IEEE Syst. J., vol. 14, no. 1, pp. 132-143, Mar. 2020.

[108] Y. Mao, J. Zhang, and K. B. Letaief, "A Lyapunov optimization approach for green cellular networks with hybrid energy supplies," IEEE J. Sel. Areas Commun., vol. 33, no. 12, pp. 2463-2477, Dec. 2015.

[109] J. Yang and S. Ulukus, "Optimal packet scheduling in an energy harvesting communication system," IEEE Trans. Commun., vol. 60, no. 1 , pp. 220-230, Jan. 2012.

[110] M. A. Antepli, E. Uysal-Biyikoglu, and H. Erkal, "Optimal packet scheduling on an energy harvesting broadcast link," IEEE J. Sel. Areas Commun., vol. 29, no. 8, pp. 1721-1731, Sep. 2011.

[111] F. M. Ozcelik, G. Uctu, and E. Uysal-Biyikoglu, "Minimization of transmission duration of data packets over an energy harvesting fading channel," IEEE Commun. Lett., vol. 16, no. 12, pp. 1968-1971, Dec. 2012.

[112] O. Ozel, K. Tutuncuoglu, J. Yang, S. Ulukus, and A. Yener, "Transmission with energy harvesting nodes in fading wireless channels: Optima policies," IEEE J. Sel. Areas Commun., vol. 29, no. 8, pp. 1732-1743, Sep. 2011.

[113] S. Zhou, J. Gong, and Z. Niu, "Sleep control for base stations powered by heterogeneous energy sources," in Proc. Int. Conf. on ICT Converg. (ICTC), Jeju Island, South Korea, Oct. 2013, pp. 666-670.

[114] J. Gong, J. S. Thompson, S. Zhou, and Z. Niu, "Base station sleeping and resource allocation in renewable energy powered cellular networks," IEEE Trans. Commun., vol. 62, no. 11, pp. 3801-3813, Nov. 2014.

[115] T. Han, X. Huang, and N. Ansari, "Energy agile packet scheduling to leverage green energy for next generation cellular networks," in Proc. IEEE Int. Conf. Commun. (ICC), Budapest, Hungary, Jun. 2013, pp. 3650-3654.

[116] D. Benda, X. Chu, S. Sun, T. Q. S. Quek, and A. Buckley, "Renewable energy sharing among base stations as a min-cost-max-flow optimiza- tion problem," IEEE Trans. Green Commun. Netw., vol. 3, no. 1, pp. 67-78, Mar. 2019.

[117] X. Huang, T. Han, and N. Ansari, "Smart grid enabled mobile networks: Jointly optimizing BS operation and power distribution," IEEE/ACM Trans. Netw., vol. 25, no. 3, pp. 1832-1845, Jun. 2017.

[118] D. Han, S. Li, Y. Peng, and Z. Chen, "Energy sharing-based energy and user joint allocation method in heterogeneous network," IEEE Access, vol. 8, pp. $37077-37086,2020$.

[119] J. Xu, Yinghao Guo, and R. Zhang, "CoMP meets energy harvesting: A new communication and energy cooperation paradigm," in Proc. IEEE Global Commun. Conf. (GLOBECOM), Atlanta, GA, USA, Dec. 2013, pp. 2508-2513.

[120] V. Chamola and B. Sikdar, "Resource provisioning and dimensioning for solar powered cellular base stations," in Proc. IEEE Global Commun. Conf. (GLOBECOM), Austin, TX, USA, Dec. 2014, pp. 24982503

[121] — , "A multistate Markov model for dimensioning solar powered cellular base stations," IEEE Trans. Sustain. Energy, vol. 6, no. 4, pp. 1650-1652, Oct. 2015.

[122] — "Outage estimation for solar powered cellular base stations," in Proc. IEEE Int. Conf. Commun. (ICC), London, UK, Jun. 2015, pp. $172-177$

[123] D. Niyato, E. Hossain, and A. Fallahi, "Sleep and wakeup strategies in solar-powered wireless sensor/mesh networks: Performance analysis and optimization," IEEE Trans. Mob. Comput., vol. 6, no. 2, pp. 221236, Feb. 2007.

[124] D. Benda, S. Sun, X. Chu, T. Q. S. Quek, and A. Buckley, "PV cell angle optimization for energy generation-consumption matching in a solar powered cellular network," IEEE Trans. Green Commun. Netw. vol. 2, no. 1, pp. 40-48, Mar. 2018.

[125] L. X. Cai, H. V. Poor, Y. Liu, T. H. Luan, X. Shen, and J. W. Mark, "Dimensioning network deployment and resource management in green mesh networks," IEEE Wirel. Commun., vol. 18, no. 5, pp. 58-65, Oct. 2011.

[126] T. Pamuklu and C. Ersoy, "Optimization of renewable green base station deployment," in Proc. IEEE Int. Conf. Green Comput. Commun. and IEEE Internet of Things and IEEE Cyber, Physical and Social Computing, Beijing, China, Aug. 2013, pp. 59-63.

[127] M. Zheng, P. Pawelczak, S. Stanczak, and H. Yu, "Planning of cellular networks enhanced by energy harvesting," IEEE Commun. Lett., vol. 17, no. 6, pp. 1092-1095, Jun. 2013.

[128] E. Oh, B. Krishnamachari, X. Liu, and Z. Niu, "Toward dynamic energy-efficient operation of cellular network infrastructure," IEEE Commun. Mag., vol. 49, no. 6, pp. 56-61, Jun. 2011.

[129] J. Zhou, M. Li, L. Liu, X. She, and L. Chen, "Energy source aware target cell selection and coverage optimization for power saving in cellular networks," in Proc. IEEE/ACM Int. Conf. on Green Comput. and Commun., Int. Conf. Cyber, Physical and Social Comput., Hangzhou, China, Oct. 2010, pp. 1-8.

[130] Q. Fan and N. Ansari, "Green energy aware user association in heterogeneous networks," in Proc. IEEE Wireless Commun. Netw. Conf. (WCNC), Doha, Qatar, Apr. 2016, pp. 1-6

[131] X. Huang and N. Ansari, "Energy sharing within EH-enabled wireless communication networks," IEEE Wirel. Commun., vol. 22, no. 3, pp. 144-149, Jun. 2015.

[132] X. Huang and N. Ansari, "Energy sharing within eh-enabled wireless communication networks," IEEE Trans. Wirel. Commun., vol. 22, no. 3 , pp. 144-149, Jun. 2015

[133] D. Benda, S. Sun, X. Chu, A. Buckley, and T. Q. S. Quek, "PV cell orientation angles optimization for a base station equipped with several PV cells," IEEE Trans. Green Commun. Netw., vol. 4, no. 1, pp. 194208, Mar. 2020.

[134] D. Benda, X. Chu, S. Sun, T. Q. S. Quek, and A. Buckley, "PV cell orientation angle optimization for a solar energy harvesting base station," in Proc. IEEE Global Commun. Conf. (GLOBECOM), Singapore, Dec. 2017, pp. 1-6.

[135] P. Nema, R. Nema, and S. Rangnekar, "Minimization of green house gases emission by using hybrid energy system for telephony base station site application," Renew. Sust. Energ. Rev., vol. 14, no. 6, pp. 1635-1639, Aug. 2010. [Online]. Available: https://www.sciencedirect.com/science/article/pii/S1364032110000511

[136] J. Kaldellis and I. Ninou, "Energy balance analysis of combined photovoltaic-diesel powered telecommunication stations," Int. J. Electric. Power Energy Syst., vol. 33, pp. 1739-1749, Oct. 2011.

[137] M. Carreno and L. Nuaymi, "Renewable energy use in cellular networks," in Proc. IEEE 77th Veh. Technol. Conf. (VTC Spring), Dresden, Germany, Jun. 2013, pp. 1-6. 
[138] M. Díaz, R. Villafáfila, D. Montesinos-Miracle, and A. Sudria-Andreu, "Study of optimization design criteria for stand-alone hybrid renewable power systems," Renew. Energy Power Quality J., pp. 1266-1270, Mar. 2013.

[139] V. A. Ani and A. N. Nzeako, "Potentials of optimized hybrid system in powering off-grid macro base transmitter station site," Int. J. Renew. Energy Res., vol. 3, no. 4, pp. 861-871, Jan. 2013

[140] D. Ike, A. Adoghe, and A. Abdulkareem, "Analysis of telecom base stations powered by solar energy," Int. J. Scientific Technol. Res., vol. 3, no. 4, pp. 369-374, Apr. 2014.

141] S. Goel and S. M. Ali, "Hybrid energy systems for off-grid remote telecom tower in Odisha, India," Int. J. Ambient. Energy, vol. 36, no. 3 , pp. 116-122, May 2015.

[142] M. Alsharif, "A solar energy solution for sustainable third generation mobile networks," Energies, vol. 10, no. 4, p. 429, Mar. 2017.

[143] M. H. Alsharif, "Comparative analysis of solar-powered base stations for green mobile networks," Energies, vol. 10, no. 8, Aug. 2017. [Online]. Available: https://www.mdpi.com/1996-1073/10/8/1208

[144] M. S. Hossain, K. Ziaul Islam, A. Jahid, K. M. Rahman, S. Ahmed, and M. H. Alsharif, "Renewable energy-aware sustainable cellular networks with load balancing and energy-sharing technique," Sustainability, vol. 12, no. 22, Nov. 2020.

[145] S. Chandrasekharan, K. Gomez, A. Al-Hourani, S. Kandeepan, T. Rasheed, L. Goratti, L. Reynaud, D. Grace, I. Bucaille, T. Wirth, and S. Allsopp, "Designing and implementing future aerial communication networks," IEEE Commun. Mag., vol. 54, no. 5, pp. 26-34, May 2016.

[146] Q. Wu, Y. Zeng, and R. Zhang, "Joint trajectory and communication design for multi-UAV enabled wireless networks," IEEE Trans. Wirel. Commun., vol. 17, no. 3, pp. 2109-2121, Mar. 2018

[147] A. Alsharoa, H. Ghazzai, A. Kadri, and A. E. Kamal, "Spatial and temporal management of cellular HetNets with multiple solar powered drones," IEEE Trans. Mob. Comput., vol. 19, no. 4, pp. 954-968, Apr. 2020.

[148] Y. Sun, D. Xu, D. W. K. Ng, L. Dai, and R. Schober, "Optimal 3D-trajectory design and resource allocation for solar-powered UAV communication systems," IEEE Trans. Commun., vol. 67, no. 6, pp 4281-4298, Jun. 2019.

[149] S. Seng, G. Yang, X. Li, H. Ji, and C. Luo, "Energy-efficient communications in solar-powered unmanned aerial systems," in Proc. IEEE Global Commun. Conf. (GLOBECOM), Taipei, Taiwan, Dec. 2020, pp. $1-6$.

[150] Y. Zeng, X. Xu, and R. Zhang, "Trajectory design for completion time minimization in UAV-enabled multicasting," IEEE Trans. Wirel. Commun., vol. 17, no. 4, pp. 2233-2246, Apr. 2018

[151] M. Mozaffari, W. Saad, M. Bennis, and M. Debbah, "Efficient deployment of multiple unmanned aerial vehicles for optimal wireless coverage," IEEE Commun. Lett., vol. 20, no. 8, pp. 1647-1650, Aug. 2016.

[152] Q. Wu, J. Xu, and R. Zhang, "Capacity characterization of UAVenabled two-user broadcast channel," IEEE J. Sel. Areas Commun., vol. 36 , no. 9 , pp. $1955-1971$, Sep. 2018

[153] J. Gong, T.-H. Chang, C. Shen, and X. Chen, "Flight time minimization of UAV for data collection over wireless sensor networks," IEEE $J$. Sel. Areas Commun., vol. 36, no. 9, pp. 1942-1954, Sep. 2018.

[154] P. Oettershagen, A. Melzer, T. Mantel, K. Rudin, T. Stastny, B. Wawrzacz, T. Hinzmann, K. Alexis, and R. Siegwart, "Perpetual flight with a small solar-powered UAV: Flight results, performance analysis and model validation," in Proc. IEEE Aerospace Conf., Big Sky, MT, USA, Mar. 2016, pp. 1-8.

[155] S. Morton, R. D'Sa, and N. Papanikolopoulos, "Solar powered UAV: Design and experiments," in Proc. IEEE/RSJ Int. Conf. on Intelligent Robots and Syst. (IROS), Hamburg, Germany, Oct. 2015, pp. 24602466

[156] M. Pozza, A. Rao, H. Flinck, and S. Tarkoma, "Network-in-a-box: A survey about on-demand flexible networks," IEEE Commun. Surv. Tutor, vol. 20, no. 3, pp. 2407-2428, 3rd Quart. 2018.

[157] D. Iland and E. M. Belding, "Emergenet: Robust, rapidly deployable cellular networks," IEEE Commun. Mag., vol. 52, no. 12, pp. 74-80, Dec. 2014.

[158] I. Ghaznavi, K. Heimerl, U. Muneer, A. Hamid, K. Ali, T. Parikh, and U. Saif, "Rescue base station," in Proc. 5th ACM Symp. on Comput. for Development. New York, NY, USA: Association for Computing Machinery, 2014, p. 53-62. [Online]. Available: https://doi.org/10.1145/2674377.2674392

[159] RKTPL, "GSM Network-in-a-Box," https://rktelesystem.com/rktplgroup/gsm-network-in-box/, accessed: April. 2021.
[160] Fairwaves, "UmSITE complete mobile network in a single tower mounted base station," https://fairwaves.co/products/, accessed: April. 2021.

[161] A. Rana, J. McCoskey, and W. Check, "VSAT technology, trends, and applications," Proc. of the IEEE, vol. 78, no. 7, pp. 1087-1095, Jul. 1990.

[162] K. C. Sri Kavya and S. K. K. and, "Rural tele-communication using VSAT technology: A review," Int. J. Pure App. Math., vol. 117, no. 18 , pp. 155-162, 2017.

[163] D. Nath and Vishnu-Mohan, "Satellite connectivity to remote areas and e-services for development: Initiatives through post office telekiosks in Bhutan," International Telecommunication Union (ITU), Tech Rep., Dec. 2009. [Online]. Available: https://www.itu.int/en/ITUD/Technology/Documents/RuralCommunications/Bhutan-Report.pdf

[164] GlobalTT, "Service \& Solution / Solar Panels," https://www.globaltt.com/en/Products-SolarPanels-Vsat.html.

[165] SOLARCOM, "VSAT Terminals," https://www.solarcomfrance.com/terminauxvsat.html.

[166] MEAPAC, "Services \& Support / VSAT," https://meapacservices.com/services-\%26-support.

[167] SpaceX, "Starlink," https://www.starlink.com/.

[168] OneWeb, "OneWeb satellite constellation," https://www.oneweb.world/network.

[169] Amazon, "Project Kuiper," https://www.amazon.jobs/en/teams/projectkuiper.

[170] Telesat, "Telesat Lightspeed," https://www.telesat.com/leo-satellites/.

[171] W. Sadd, M. Bennis, and M. Chen, "A vision of $6 \mathrm{G}$ wireless systems: Applications, trends, technologies, and open research problems," IEEE Netw., vol. 34, no. 3, pp. 134-142, May 2020.

[172] B. Zong, C. Fan, X. Wang, X. Duan, B. Wang, and J. Wang, "6G technologies: Key drivers, core requirements, system architectures, and enabling technologies," IEEE Veh. Technol. Mag., vol. 14, no. 3, pp. 18-27, Sep 2019.

[173] Z. Zhang, Y. Xiao, Z. Ma, M. Xiao, Z. Ding, X. Lei, G. K. Karagiannidis, and P. Fan, "6G wireless networks: Vision, requirements, architecture, and key technologies," IEEE Veh. Technol. Mag., vol. 14, no. 3, pp. 28-41, Sep 2019.

[174] N. Piovesan, D. López-Pérez, M. Miozzo, and P. Dini, "Joint load control and energy sharing for renewable powered small base stations: A machine learning approach," IEEE Trans. Green Commun. Netw. vol. 5, no. 1, pp. 512-525, Mar 2021.

[175] Y. Wei, F. R. Yu, M. Song, and Z. Han, "User scheduling and resource allocation in hetnets with hybrid energy supply: An actorcritic reinforcement learning approach," IEEE Trans. Wirel. Commun., vol. 17, no. 1, pp. 680-692, Jan 2018.

[176] N. Rajatheva, I. Atzeni, E. Bjornson, A. Bourdoux, S. Buzzi, J.-B. Dore, S. Erkucuk, M. Fuentes, K. Guan, Y. Hu, X. Huang, J. Hulkkonen, J. M. Jornet, M. Katz, R. Nilsson, E. Panayirci, K. Rabie, N. Rajapaksha, M. Salehi, H. Sarieddeen, T. Svensson, O. Tervo, A. Tolli, Q. Wu, and W. Xu, "White paper on broadband connectivity in 6G," 2020. [Online]. Available: https://arxiv.org/abs/2004.14247

[177] F. Tariq, M. R. A. Khandaker, K.-K. Wong, M. A. Imran, M. Bennis, and M. Debbah, "A speculative study on 6G," IEEE Wirel. Commun., vol. 27, no. 4, pp. 118-125, Aug. 2020.

[178] X. Zhu, Y. Yang, z. liu, P. Zhang, x. tao, S. Li, Z. Chen, x. ma, C.-L. I., S. Han, K. Li, c. pan, x. shen, z. zheng, Y. Guo, Z. Ding, H. Haas, w. tong, p. zhu, and L. Hanzo, "Towards 6G wireless communication networks: Vision, enabling technologies, and new paradigm shifts," Sci. China Inf. Sci., vol. 64, Nov. 2020

[179] Z. Wang, D. Tsonev, S. Videv, and H. Haas, "On the design of a solarpanel receiver for optical wireless communications with simultaneous energy harvesting," IEEE J. Sel. Areas Commun., vol. 33, no. 8, pp. 1612-1623, Jan. 2015.

[180] — " "Towards self-powered solar panel receiver for optical wireless communication," in Proc. IEEE Int. Conf. Commun. (ICC), Sydney, Australia, Jun. 2014, pp. 3348-3353.

[181] H. Haas, S. Videv, S. Das, J. Fakidis, and H. Stewart, "Solar cell receiver free-space optical for 5G backhaul," in Proc. Optical Fiber Communications Conference and Exhibition (OFC), San Diego, USA, Mar. 2019, pp. 1-3.

[182] K. Poularakis, G. Iosifidis, and L. Tassiulas, "Joint caching and base station activation for green heterogeneous cellular networks," in Proc IEEE Int. Conf. Commun. (ICC), London, UK, Jun. 2015, pp. 3364 3369.

[183] M. I. A. Zahed, I. Ahmad, D. Habibi, Q. V. Phung, and L. Zhang, "A cooperative green content caching technique for next generation communication networks," IEEE Trans. Netw. Service Manag, vol. 17, no. 1 , pp. $375-388,2020$. 
[184] A. Khreishah, H. Bany Salameh, I. Khalil, and A. Gharaibeh, "Renewable energy-aware joint caching and routing for green communication networks," IEEE Syst. J., vol. 12, no. 1, pp. 768-777, 2018.

[185] F. Guo, H. Zhang, X. Li, H. Ji, and V. C. M. Leung, "Joint optimization of caching and association in energy-harvesting-powered small-cell networks," IEEE Trans. Veh. Technol., vol. 67, no. 7, pp. 6469-6480, 2018.

[186] E. Calvanese Strinati, S. Barbarossa, J. L. Gonzalez-Jimenez, D. Ktenas, N. Cassiau, L. Maret, and C. Dehos, "6G: The next frontier: From holographic messaging to artificial intelligence using subterahertz and visible light communication," IEEE Vehicular Technology Magazine, vol. 14, no. 3, pp. 42-50, Aug. 2019. 